Article

\title{
Reservoir Operation Rules for Controlling Algal Blooms in a Tributary to the Impoundment of Three Gorges Dam
}

\author{
Jijian Lian ${ }^{1}$, Ye Yao ${ }^{1}$, Chao Ma ${ }^{1, *}$ and Qizhong Guo ${ }^{2}$
}

1 State Key Laboratory of Hydraulic Engineering Simulation and Safety, Tianjin University, Tianjin 300072, China; E-Mails: tju_luntan@126.com (J.L.); yaoye-111@163.com (Y.Y.)

2 Department of Civil and Environmental Engineering, Rutgers, The State University of New Jersey, Piscataway, NJ 08854, USA; E-Mail: qguo@rci.rutgers.edu

* Author to whom correspondence should be addressed; E-Mail: mac_tju@126.com; Tel.: +86-22-27401127; Fax: +86-22-27401123.

External Editor: Miklas Scholz

Received: 30 July 2014; in revised form: 24 September 2014 / Accepted: 13 October 2014 / Published: 22 October 2014

Abstract: Since the first impoundment of Three Gorges Dam in 2003, algal blooms occur frequently in the near-dam tributaries. It is widely recognized that the impoundment-induced change in hydrodynamic condition with the lower current velocity will make the eutrophication problem even more severe when an excessive amount of nutrients is already loaded into a reservoir and/or its tributaries. Operation tests carried out by Three Gorges Corporation in 2010 point to some feasible reservoir operation schemes that may have positive impacts on reducing the algal bloom level. In our study, an attempt is made to obtain, through a numerical hydrodynamic and water quality modeling and analysis, the reservoir operation rules that would reduce the level of algal blooms in the Xiangxi River (XXR), a near-dam tributary. Water movements and algal blooms in XXR are simulated and analyzed under different scenarios of one-day water discharge fluctuation or two-week water level variation. The model results demonstrate that the reservoir operations can further increase the water exchange between the mainstream of the Three Gorges Reservoir (TGR) and the XXR tributary and thus move a larger amount of algae into the deep water where it will die. Analysis of the model results indicate that the water discharge fluctuation constituted of a lower valley-load flow and a larger flow difference for the short-term operation (within a day), the rise in water level for the medium-term operation (e.g., over 
weeks), and the combination of the above two for the long-term operation (e.g., over months) can be the feasible reservoir operation rules in the non-flood season for TGR.

Keywords: Three Gorges Reservoir; Xiangxi River; reservoir operation rules; algal bloom; density current

\section{Introduction}

Development of reservoirs with large regulation capacity is an effective way to utilize water resources, produce hydropower energy and reduce flood risk. However, the hydrodynamic condition after impoundment significantly changes from the natural state with lower water velocity and longer residence time, resulting in deteriorated water quality and eutrophication problems $[1,2]$. For the largest man-made reservoir system in the world, the Three Gorges Reservoir (TGR), according to the annual report of eco-environmental monitoring of TGR released by Executive Office of State Council TGP Construction Committee [3], more than $30 \%$ of the monitoring sections in the major tributaries are in the state of high eutrophication, and algal blooms occur in over 20 tributaries from March to October every year, such as Xiangxi River (XXR), Tongzhuang River and Daning River. Algal blooms occurred in XXR seriously affect local residents' life with turbid and stinky water [4,5]. Harmful algal blooms with toxins as a prime agent of water quality deterioration also result in a loss of water for recreation and drinking [6-8]. In order to alleviate the increasing algal bloom problems in TGR, more and more attention is being paid to the feasible solutions.

In the last decade, long-term field monitoring and researches of algal blooms in the near-dam tributaries of TGR have been carried out by government, corporations, colleges and research institutions [9-14]. Agreement is reached that the significant change in hydrodynamic condition is a compounding factor for the more frequent occurrence of algal blooms after the impoundment of Three Gorges Dam (TGD) with its effect on the transport of nutrient loads, water temperature structure and environment for algae growth [1,9,15-17]. An operation test is carried out by Three Gorges Corporation in 2010, and the result points to some feasible reservoir operation schemes that may have positive impacts on reducing the algal bloom level in the near-dam tributaries. With the help of measured data, influencing factors on water movement of the tributaries and their influence on algal blooms are found. Ji [18] and Yang [2] point out that the reverse density flow produced by water level fluctuation and water temperature difference both have positive impacts on water exchange and interaction between the mainstream and the tributaries. Jiang [19] verifies the result and emphasizes that thermal stratified flow by water temperature difference should be considered for the algal bloom control. Then, analysis is conducted to validate that a wave-type water release operation is beneficial in reducing algal bloom in the tributary [20]. Furthermore, a feasible water level process of TGR is also demonstrated to be helpful for controlling phytoplankton blooms in the tributary bays by the analysis of mixing depth [21]. Besides above, effects of environment factors and operation of TGR on algal blooms in the near-dam tributaries are also discussed. Several numerical models have been developed to predict the algal blooms in tributaries of TGR with analysis of hydrodynamic condition, nutrient concentration, temperature, and light illumination [22-24]. Zhou [25,26] proposes that water exchange 
and interaction are enhanced by daily peak-load regulation between the mainstream and the XXR. Ma [27,28] describes water movement in the tributaries under multi-timescale operations of TGR and develops multi-objective operation rules based on one-dimensional numerical model in non-flood season for TGR with water quality considered. With above pieces of work, some puzzles have been clarified for a clearer understanding of the mechanism of algal blooms in TGR. However, the relationship among operation of TGR, hydrodynamics condition and algal bloom still should be further studied and quantified that will form the basis for proposing a feasible operation rule for TGR. Therefore, an attempt is made in this study to obtain, through a numerical hydrodynamic and water quality modeling and analysis, the reservoir operation rules that would reduce level of algal blooms in the Xiangxi River (XXR), a near-dam tributary.

The paper is arranged as follows. In Section 2, the study area is introduced in detail. From consideration of remarkable vertical flow structure of TGR as a river-type reservoir, a hydrodynamic and water quality model for the mainstream of TGR and tributary XXR (TGR-XXR model) is developed and calibrated based on the CE-QUAL-W2 model that has been applied successfully to many lakes, estuaries and reservoirs [29-34]. In Section 3, water movement and algal bloom process in XXR are simulated and analyzed under 11 different scenarios of short-term daily water discharge fluctuations or medium-term water level variations using chlorophyll a as the indicator for algal blooms. Then, operation rules for reducing level of algal blooms are proposed in the concluding Section 4.

\section{Materials and Methods}

\subsection{Study Area}

The TGD is located in the middle reach of the Yangtze River in China, creating TGR with a total storage capacity of $393 \times 10^{8} \mathrm{~m}^{3}$ and a regulation storage capacity of $221.5 \times 10^{8} \mathrm{~m}^{3}$. Backwater zone length of TGR is $660 \mathrm{~km}$ from the dam, and the reservoir has a total drainage basin area of 55,742 $\mathrm{km}^{2}$. Average annual runoff is $14,000 \mathrm{~m}^{3} / \mathrm{s}$, and inflow ranges from $3000 \mathrm{~m}^{3} / \mathrm{s}$ to $30,000 \mathrm{~m}^{3} / \mathrm{s} \mathrm{normally}$ within a year. The normal reservoir level is $175.0 \mathrm{~m}$ and the flood control level is $145.0 \mathrm{~m}$. XXR is one of the largest near-dam tributaries of TGR in Hubei Province, located only $31.3 \mathrm{~km}$ upward from the TGD $\left(110^{\circ} 25^{\prime}-111^{\circ} 06^{\prime} \mathrm{E}, 31^{\circ} 04^{\prime}-31^{\circ} 34^{\prime} \mathrm{N}\right)$, which flows southwardly into the Yangtze River. The mainstream of XXR is $33 \mathrm{~km}$ long and the total length of XXR is $97.4 \mathrm{~km}$ with a drainage basin area of $3099 \mathrm{~km}^{2}$. Average annual runoff is $65.5 \mathrm{~m}^{3} / \mathrm{s}$, and inflow ranges from $20 \mathrm{~m}^{3} / \mathrm{s}$ to $200 \mathrm{~m}^{3} / \mathrm{s}$ normally within a year. Figure 1 shows location of TGD and sketch map of the study area (river reaches in red).

\subsection{Methodology}

\subsubsection{Model Introduction}

CE-QUAL-W2 (W2) model, developed by the U.S. Army Corps of Engineers' Waterways Experiment Station, is a two-dimensional (longitudinal-vertical) hydrodynamic and water quality model [35]. Because the model assumes lateral homogeneity, it is best suited for relatively long and narrow water bodies exhibiting longitudinal and vertical water quality gradients, similar to the TGR. Water surface 
elevations, velocities and temperatures can be predicted well by the hydrodynamic module of W2 model. Furthermore, 28 constituents and over 60 derived variables can be included in the water quality module, by which the whole process of algal blooms and the transport of algae can be simulated with integrity and clarity.

Figure 1. Location of the Three Gorges Dam (TGD) and sketch map of the study area.

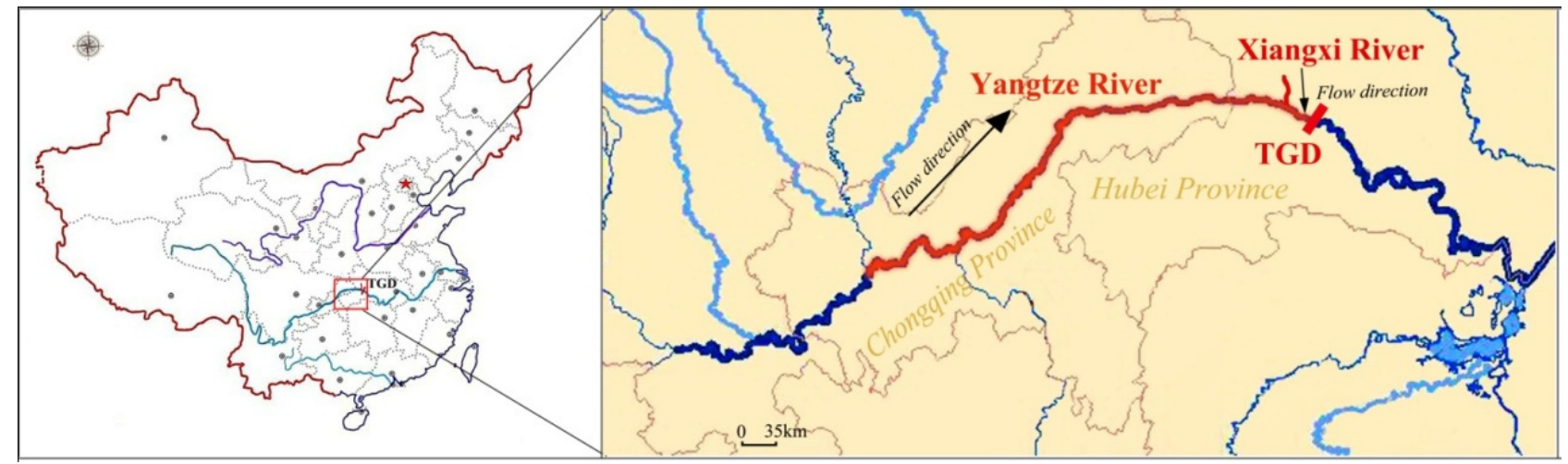

\subsubsection{Model Construction}

The TGR-XXR model is set up with two water bodies (the mainstream is wb_1 and XXR is wb_2) and eight reaches (seven reaches for the mainstream and one for XXR) according to the variation of bottom slope. The mainstream is $598.5 \mathrm{~km}$ long upwards from the TGD, and the XXR is $32 \mathrm{~km}$ long upwards from the confluence. Based upon the reservoir geometry and the computational efficiency and desirable accuracy, the model is simulated with 213 longitudinal segments, each $4.5 \mathrm{~km}$ long for wb_1 and $0.5 \mathrm{~km}$ long for wb_2. Depending on the local water depth, up to 107 vertical layers are used at each segment with a layer thickness of $2 \mathrm{~m}$. Figure 2 shows the model segmentations, and the typical segments that could be used in the model calibration and application are also labeled in it. A maximum time step of $48 \mathrm{~s}$ is adopted for the model simulation.

Figure 2. Model segmentations of TGR-XXR. (a) Sketch map of grid cross-cut of XXR; (b) Grid straight-cut of XXR; (c) Model grid plan and location of typical grids. (Number in the inset of Figure 2c represents the model segment number, e.g., 137 represents Segment 137).

(a)

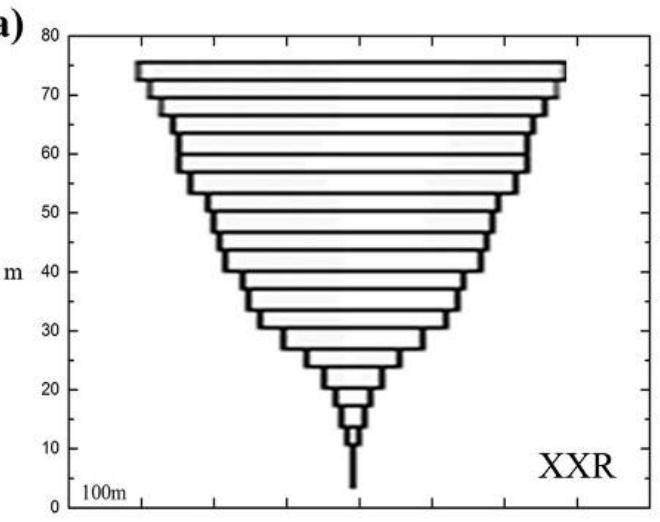

(b)

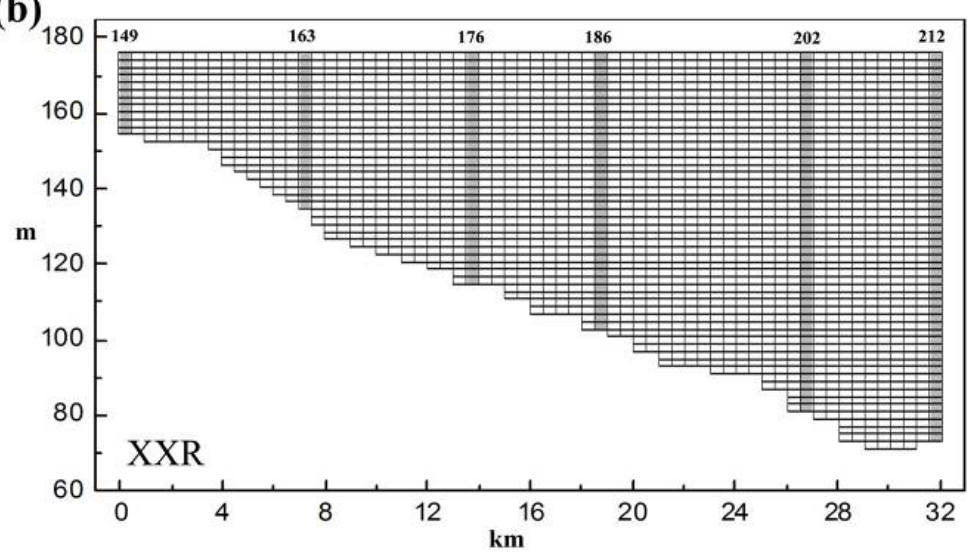


Figure 2. Cont.

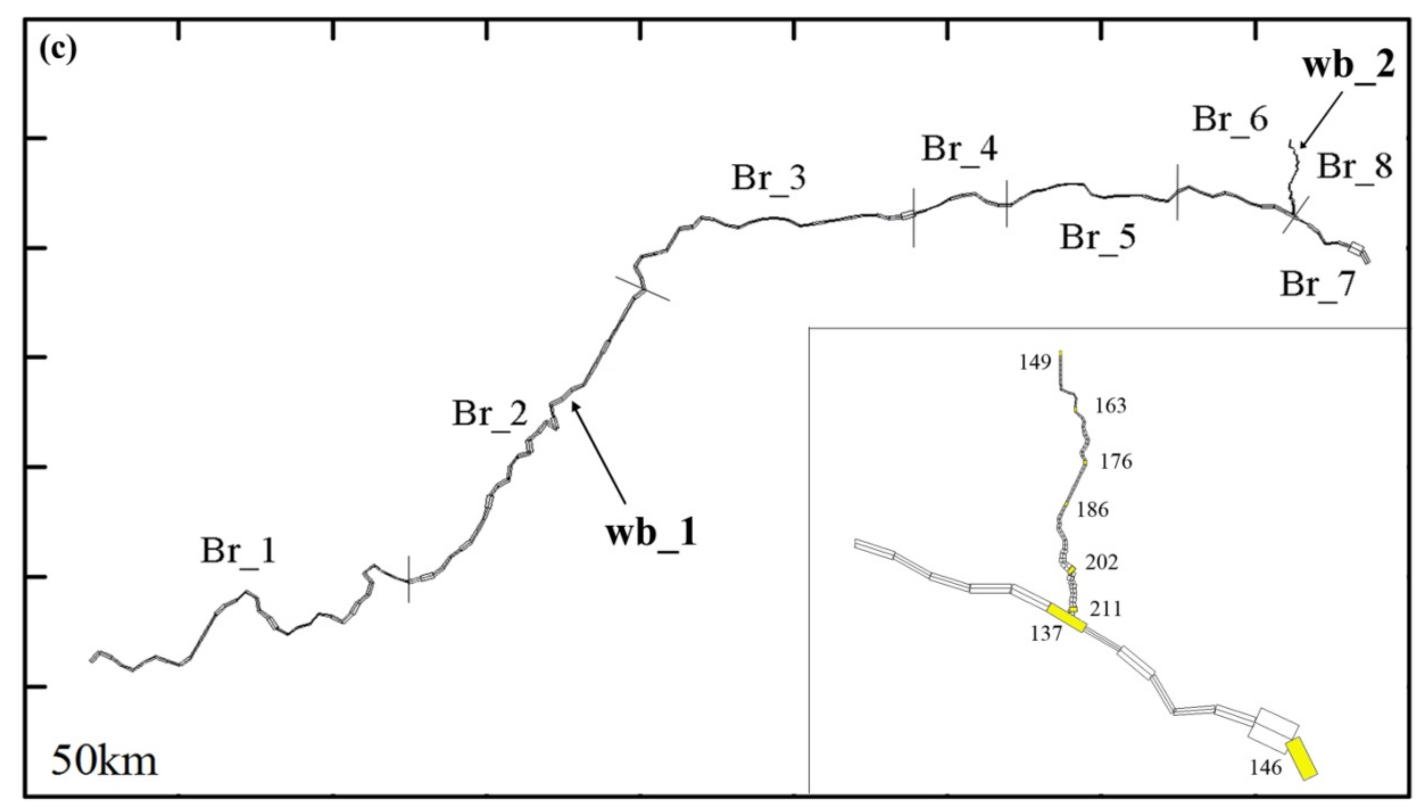

Input data for the model simulations include reservoir or river bathymetry, meteorological data (air temperature, dew point temperature, wind speed, wind direction, and percentage of cloud cover), inflow and outflow characterized by flow rate or water level, water temperature and nutrient concentration. The important calibration coefficients for the hydrodynamic module and water quality module are listed in Table 1 and their values are based upon those recommended in the past studies [35-38]. Among these calibration coefficients, Manning's friction factor, maximum algal growth rate, ammonium decay rate, and nitrate decay rate are most sensitive for the model results.

Table 1. Important coefficient for TGR-XXR model.

\begin{tabular}{lcc}
\hline Coefficient & Units & Calibration Value \\
\hline Manning's friction factor of the mainstream & - & $0.04^{\mathrm{a}}$ \\
Manning's friction factor of XXR & - & $0.025 \sim 0.023^{\mathrm{b}}$ \\
longitudinal eddy viscosity & $\mathrm{m}^{2} / \mathrm{s}$ & $1.0^{\mathrm{c}}$ \\
longitudinal eddy diffusivity & $\mathrm{m}^{2} / \mathrm{s}$ & $1.0^{\mathrm{d}}$ \\
Extinction for pure water & $\mathrm{m}^{-1}$ & $0.25^{\mathrm{c}}$ \\
Maximum algal growth rate & $\mathrm{day}^{-1}$ & $1.2^{\mathrm{c}}$ \\
Maximum algal respiration rate & $\mathrm{day}^{-1}$ & $0.04^{\mathrm{c}}$ \\
Maximum algal excretion rate & $\mathrm{day}^{-1}$ & $0.04^{\mathrm{c}}$ \\
Maximum algal mortality rate & $\mathrm{day}^{-1}$ & $0.1^{\mathrm{c}}$ \\
Algal settling rate & $\mathrm{m} \cdot \mathrm{day}^{-1}$ & $0.1^{\mathrm{c}}$ \\
Algal half-saturation for phosphorus limited growth & $\mathrm{g} \cdot \mathrm{m}^{-3}$ & $0.003^{\mathrm{c}}$ \\
Algal half-saturation for nitrogen limited growth & $\mathrm{g} \cdot \mathrm{m}^{-3}$ & $0.14^{\mathrm{c}}$ \\
Light saturation intensity at maximum photosynthetic rate & $\mathrm{W} \cdot \mathrm{m}^{-2}$ & $75^{\mathrm{c}}$ \\
Ammonium decay rate & $\mathrm{day}^{-1}$ & $0.01^{\mathrm{c}}$ \\
Nitrate decay rate & $\mathrm{day}^{-1}$ & $0.1^{\mathrm{c}}$ \\
\hline
\end{tabular}




\subsubsection{Field Data Collection}

The TGR-XXR model is calibrated with field data collected from 10 October 2008 to 15 June 2009 (Julian Day: 284-532). The meteorological data is the daily average of monitoring data at Zigui station obtained from the Meteorological Administration of Hubei Province. The inflow, outflow and water temperature are the daily data, which are provided by China Three Gorges Corporation obtained from the long-term field monitoring. China Three Gorges University carries out the field observation in XXR monthly and provides the constituent concentrations over the model calibration period.

\subsubsection{Hydrodynamic Model Calibration}

Simulation results of water surface elevation and water temperature are used to calibrate the hydrodynamic module of model, as shown in Figures 3 and 4. The statistic errors, mean absolute error (MAE) and Nash-Sutcliffe efficiency (NSE) [39] are listed in Table 2. Figure 3 and the statistical errors show that the modeled water surface elevation matches the measured data well, which rises from the initial $155.59-172.76 \mathrm{~m}$ and then falls to $145.93 \mathrm{~m}$. The comparisons of vertical profiles of water temperature at the three typical stations from November to April depicted in Figure 4 as well as the associated statistical errors show good model skill in reproducing the thermal structure of the water column. Thermal stratification is weak in the mainstream of TGR but relatively strong in XXR, which matches well with the actual situation of TGR.

Table 2. Results of statistic errors.

\begin{tabular}{cccccccc}
\hline $\begin{array}{c}\text { Statistic } \\
\text { Error }\end{array}$ & $\begin{array}{c}\text { Water Surface } \\
\text { Elevation }\end{array}$ & $\mathbf{T}$ & $\mathbf{P O}_{\mathbf{4}}$ & $\mathbf{N O}_{\mathbf{3}}-\mathbf{N}$ & $\mathbf{N H}_{\mathbf{4}}-\mathbf{N}$ & $\mathbf{D S i}$ & $\mathbf{C h l a}$ \\
\hline \multirow{2}{*}{$\mathrm{MAE}$} & $0.077(\mathrm{~m})$ & 0.416 & 0.014 & 0.108 & 0.064 & 0.849 & 5.531 \\
& & $\left({ }^{\circ} \mathrm{C}\right)$ & $\left(\mathrm{g} / \mathrm{m}^{3}\right)$ & $\left(\mathrm{g} / \mathrm{m}^{3}\right)$ & $\left(\mathrm{g} / \mathrm{m}^{3}\right)$ & $\left(\mathrm{g} / \mathrm{m}^{3}\right)$ & $(\mu \mathrm{g} / \mathrm{L})$ \\
$\mathrm{NSE}$ & 0.999 & 0.977 & 0.521 & 0.751 & 0.910 & 0.983 & 0.718 \\
\hline
\end{tabular}

Figure 3. Comparison of modeled and observed water surface elevation for TGR (location before TGD site, Segment 146 in model).

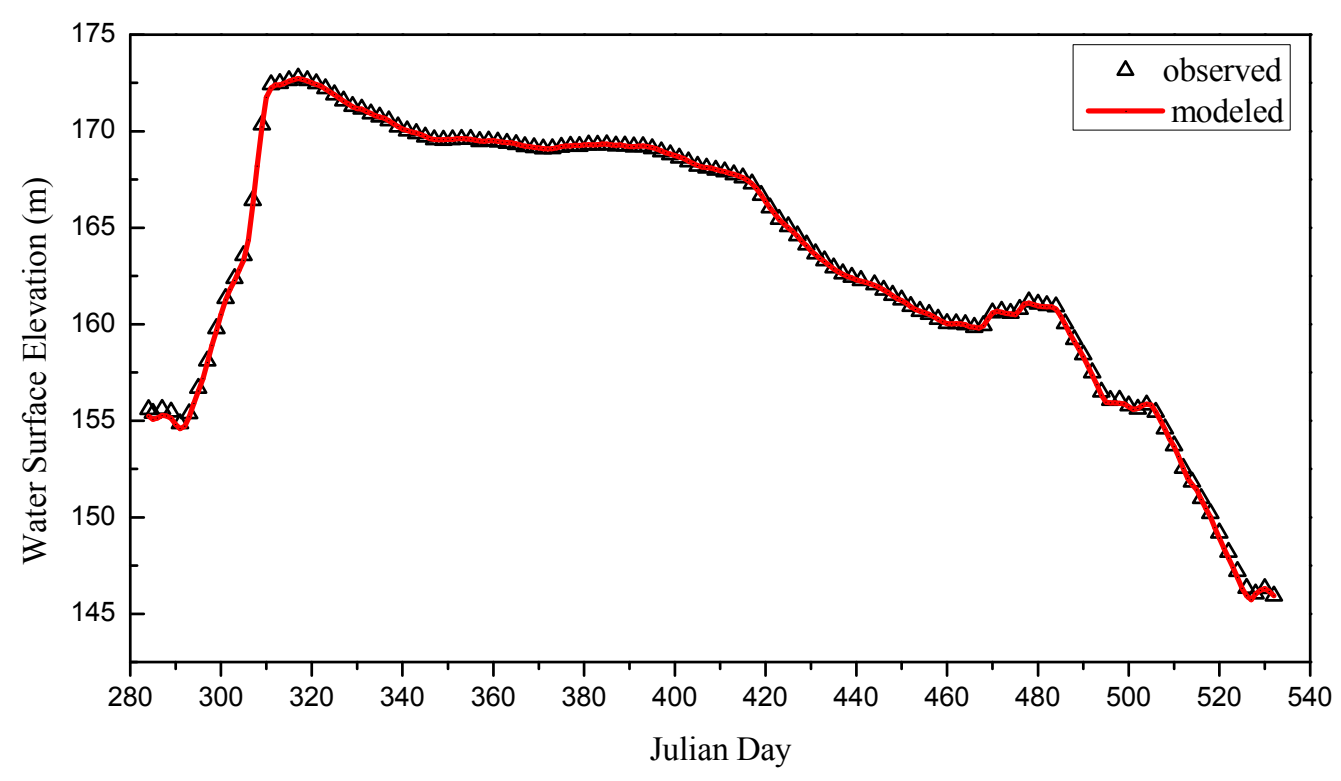


Figure 4. Comparison of modeled and observed vertical temperature profiles.
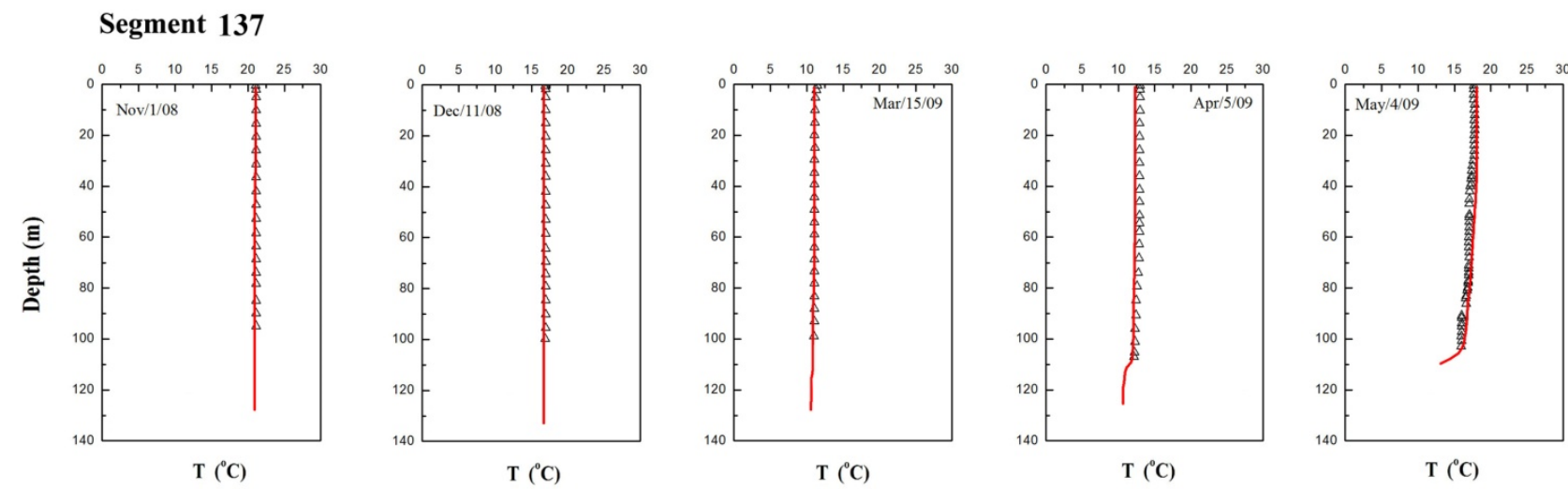

Segment 211
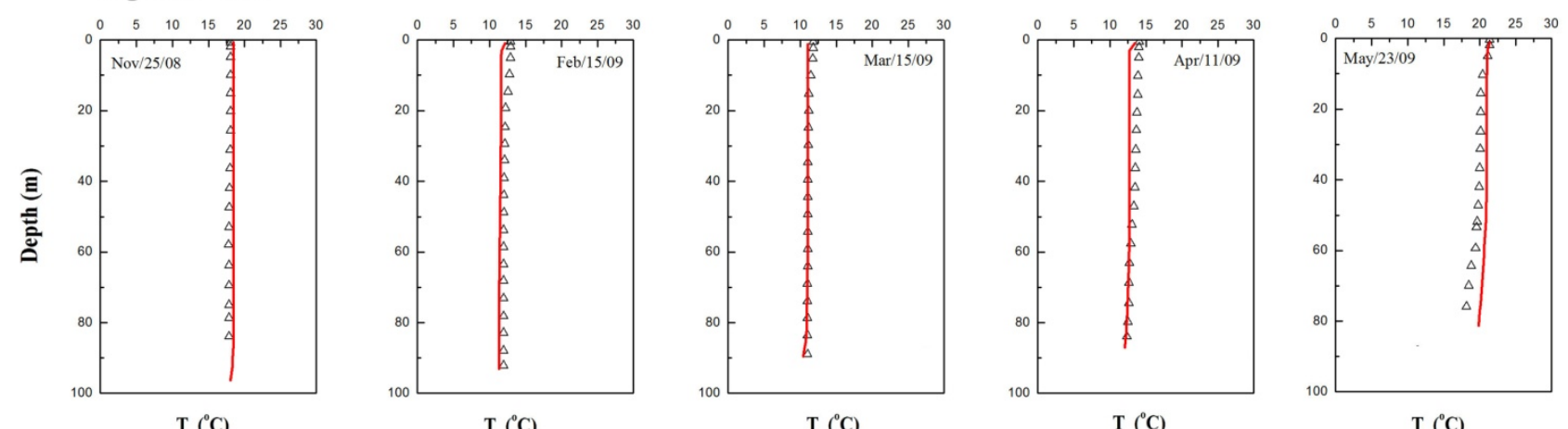

Segment 176
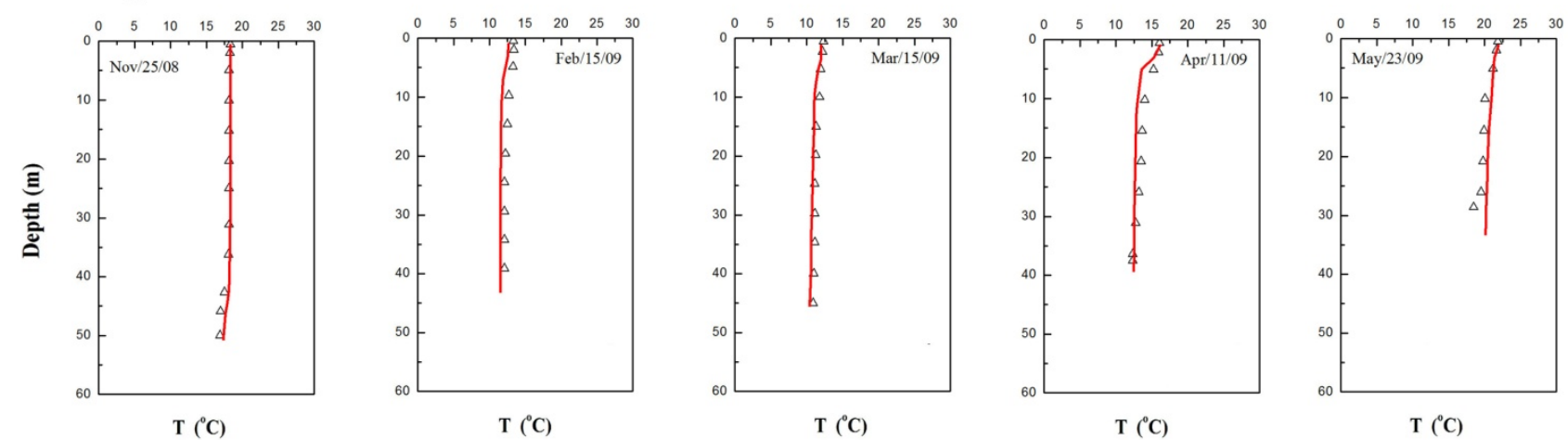

$\triangle$ Observed Modeled

\subsubsection{Water Quality Model Calibration}

The procedure used for the water quality module calibration searches for the best fit between the observed and predicted constituents including nitrogen (ammonia and nitrate), phosphorus, dissolved silica and chlorophyll a (Chla). The dominant species of algal blooms in XXR varies seasonally, and diatom is typically the dominant species of the spring algal bloom [3]. Because algal blooms do not occur in the mainstream, the calibration results shown here are only for the XXR. Comparisons of temporal variations between modeled nutrient and observed data at a typical station (Segment 176) in the upper middle reach are shown in Figure 5, and the calibration results of Chla at different stations are shown in Figure 6, with the statistic errors listed in Table 2. Visual observations and the statistic 
errors indicate that the model performed well in simulating the water quality of the mainstream of TGR and XXR.

Figure 5. Comparisons of modeled and observed nutrient concentrations (Segment 176).
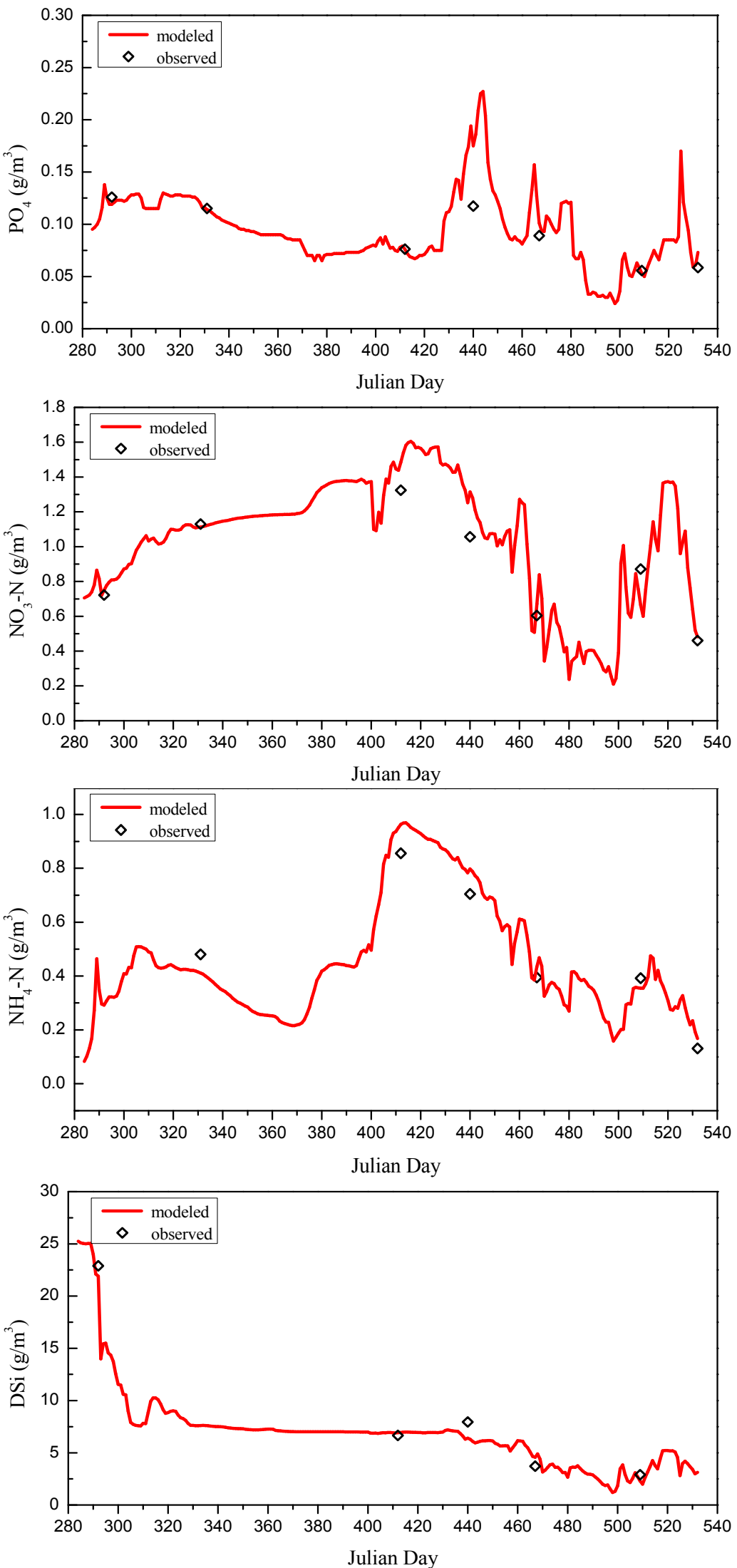
Figure 6. Comparisons of modeled and observed Chla concentration.
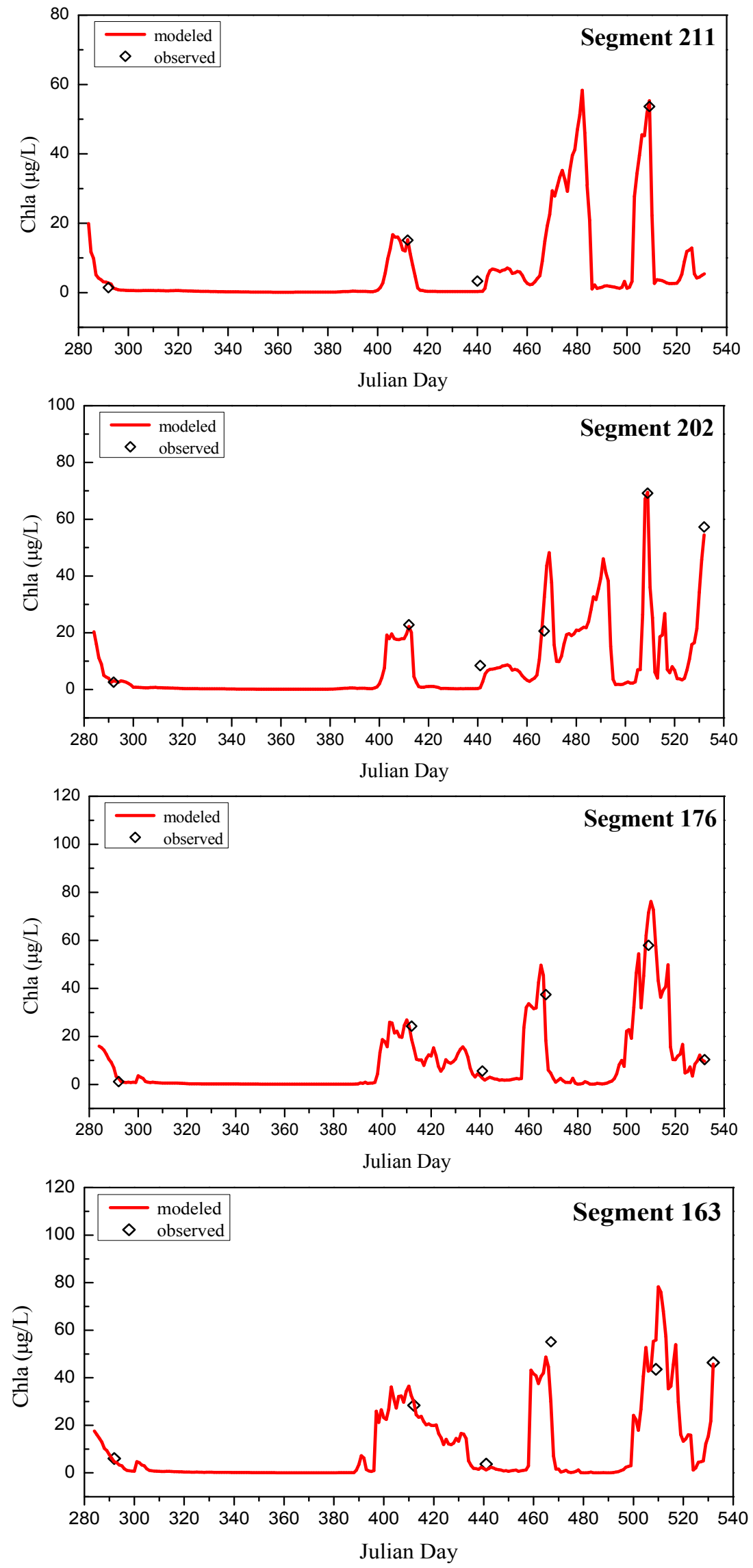


\section{Reservoir Operation Rules for Controlling Algal Blooms}

\subsection{Generalization of Water Discharge Process of TGHS}

According to the actual regulation rules, the Three Gorges Hydropower Station (TGHS) plays roles in both electricity base generation and peak-load regulation. For the flood-control, environment-maintenance, and other purposes, reservoir level is set to fall from the normal level of $175 \mathrm{~m}$ in November to the flood control level of $145 \mathrm{~m}$ in May or June of the following year, but it should be higher than $155.0 \mathrm{~m}$ before mid-May. After the impoundment of TGD, sedimentation rate at from the upstream end increases. Clear water released from TGHS and Gezhouba Hydropower Station aggravates the river bed erosion, especially in the downstream of Gezhouba Reservoir [40]. In addition, low water level has a negative effect on navigation and water supply. In order to solve the problem, average daily water discharge of TGHS is constrained to be more than $5000 \mathrm{~m}^{3} / \mathrm{s}$ in the on-flood season. During the non-flood season as well as the algal bloom season from March to June, inflow to TGR is larger than $5000 \mathrm{~m}^{3} / \mathrm{s}$, thus it is feasible to utilize the excess flow/volume to implement a reservoir regulation with a water level fluctuation for weeks.

Water discharge processes of TGHS are generalized into short-term operation (daily operation), medium-term operation (approximate two weeks) and long-term operation (for the non-flood season). For the short-term operation, due to an important role of power generation and water supply to downstream river, daily water discharge process of TGHS in non-flood season is planned according to daily inflow, release requirement and load demand with peak-load regulation. In this study, $24 \mathrm{~h}$ of a day are divided into four typical periods and four transition periods with a total of 48 time intervals (each lasts $0.5 \mathrm{~h}$ ), including valley-load period (when the discharge is the lowest) (0:00-6:00), morning peak-load period (8:00-11:00), medium-load period (12:00-17:00), and evening peak-load period (19:00-22:00). Water discharge does not change over a typical period but changes linearly over a transition period. Water discharge in the evening peak-load period (peak-load flow) is equal to that in the valley-load period (valley-load flow) plus flow difference (Figure 7). Water discharges in the morning peak-load period or the medium-load period are obtained from its ratio over that in evening peak-load period, set to be 0.85 and 0.65 , respectively. For the medium-term operation, the water level variation over a period of time is set to be three different scenarios: constant, rise or fall (Figure 8). Additionally, the long-term operation is planned step by step with periodical medium-term operation and short-term operation for a month approximately in the non-flood season. Here, the long-term operation rules are obtained from the inference based on the above two operation rules without individual simulation.

\subsection{Scenario Construction}

The calibrated model is applied to predict the influence of different timescale operation on algal blooms in XXR using Chla concentration as an indicator that is common for algae biomass evaluation [41]. Forty days (Julian Day: 0-40) are set as the simulation period in order to model an entire algal bloom process probably occurred in spring (from March to May) in XXR based on the actual situation. To separate the effects of reservoir regulation from the effects of other variables, all other variables are set to have constant values. The air temperature and dew point temperature are set to be constant at $18{ }^{\circ} \mathrm{C}$ 
and $13{ }^{\circ} \mathrm{C}$ that are the average values used during the model calibration when the algal blooms occurred. The effects of wind and cloud cover are not considered in the model. The initial reservoir water level is $160 \mathrm{~m}$, the inflow of XXR is $65.5 \mathrm{~m}^{3} / \mathrm{s}$, and the inflow of TGR and discharge of TGHS are set to be corresponding to the model demand for flow or water level in scenarios $\left(9041.875 \mathrm{~m}^{3} / \mathrm{s}\right.$ is used as the average daily discharge in most cases).

Figure 7. Water discharge scenarios for short-term operation.



Figure 8. Four types of water level variation scenarios for medium-term operation.

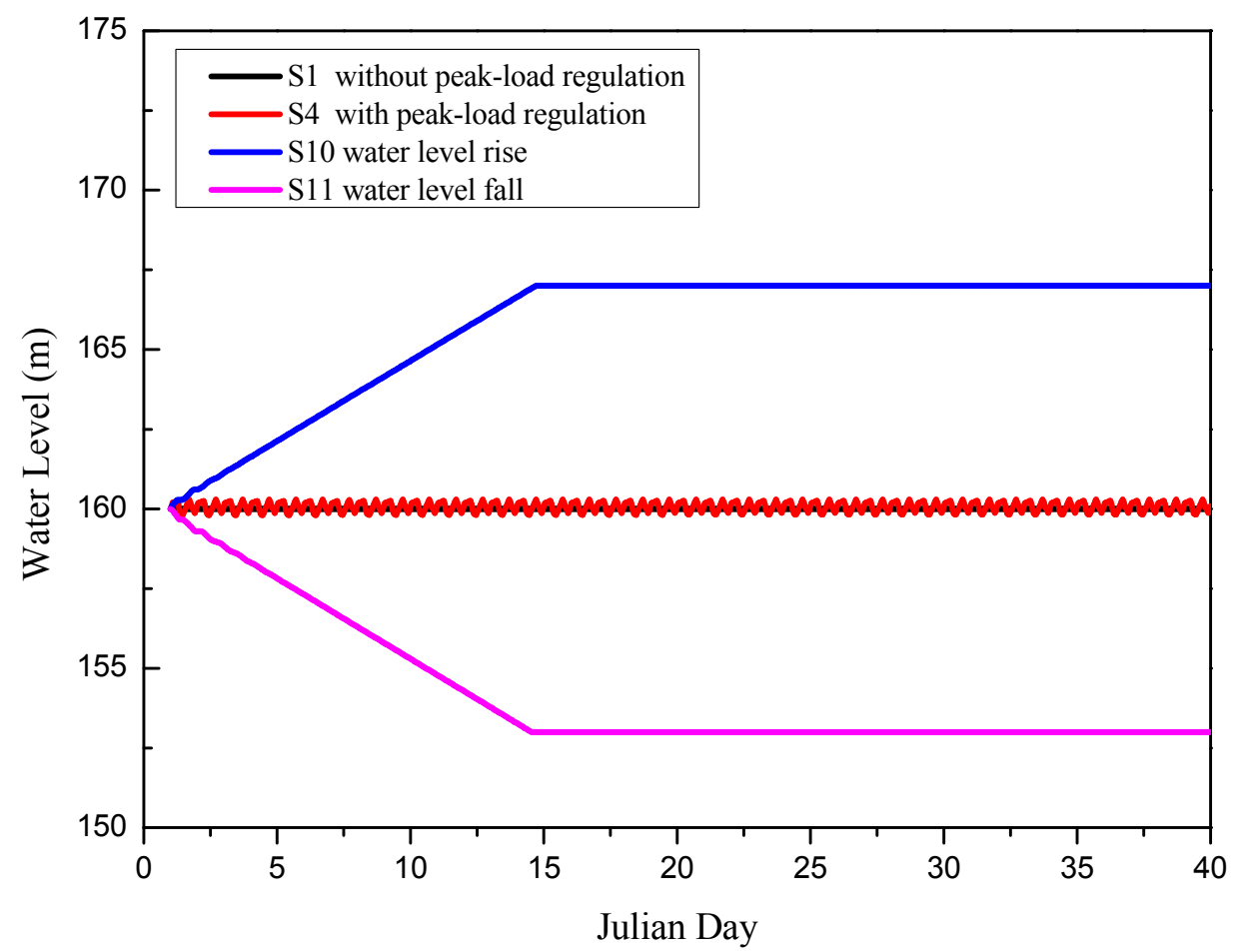


Long-term observation shows that the density current due to water temperature difference between mainstream and XXR has seasonal variation over a year [42]. The corresponding plunging position in which water flows into XXR from mainstream is different. When algal blooms occur in spring, the density current maintains that water from the mainstream plunges into the XXR from upper layers weakly and middle layers strongly. In order to maintain the same flow plunging/entrainment type as that describe above, initial and boundary water temperatures for the mainstream and XXR are set to be that as depicted in Table 3.

Table 3. Initial and boundary conditions of water temperature and constituent concentrations.

\begin{tabular}{cccccc}
\hline \multirow{2}{*}{ Constituent } & \multirow{2}{*}{ Unit } & \multicolumn{2}{c}{ Initial Condition } & \multicolumn{2}{c}{ Boundary Condition } \\
\cline { 3 - 6 } & & Mainstream & XXR & Mainstream & XXR \\
\hline $\mathrm{T}$ & ${ }^{\circ} \mathrm{C}$ & 17 & $17.5 \sim 16.5$ & 17 & 16 \\
$\mathrm{Chla}$ & $\mu \mathrm{g} / \mathrm{L}$ & 0 & 10 & 0 & 10 \\
$\mathrm{PO}_{4}$ & $\mathrm{~g} / \mathrm{m}^{3}$ & 0.1 & 0.2 & 0.1 & 0.2 \\
$\mathrm{NH}_{4}-\mathrm{N}$ & $\mathrm{g} / \mathrm{m}^{3}$ & 0.5 & 0.4 & 0.5 & 0.4 \\
$\mathrm{NO}_{3}-\mathrm{N}$ & $\mathrm{g} / \mathrm{m}^{3}$ & 1.4 & 0.5 & 1.4 & 0.5 \\
$\mathrm{DSi}$ & $\mathrm{g} / \mathrm{m}^{3}$ & 5.0 & 5.0 & 5.0 & 5.0 \\
\hline
\end{tabular}

For XXR, Zhang [43] proposes that nitrogen is mainly provided by the TGR mainstream and phosphorous is mainly from the XXR inflow. Nutrients are not the limiting factor for algal growth in TGR [44]. Thus, the boundary conditions for nutrients should be conformed to the above situation and the concentrations should be set to be sufficient for algal growth. The average Chla concentration in surface water of XXR is $10 \mu \mathrm{g} / \mathrm{L}$, and reduces gradually with the depth. The threshold value of high eutrophication of TGR is $32.59 \sim 62.81 \mu \mathrm{g} / \mathrm{L}$ [45], and the average value $47.7 \mu \mathrm{g} / \mathrm{L}$ is assumed as the threshold value of algal bloom occurrence in XXR in this study. The initial conditions and boundary conditions are depicted in Table 3.

Influence of two operation factors on algal bloom process are considered, including peak-load regulation type (short-term operation) and water level variation (medium-term operation) (Table 4). S1 S5 scenarios are operation solutions with different daily water discharge processes, in which S2 to $\mathrm{S} 5$, when compared with $\mathrm{S} 1$, aim at detecting the influence of continuous daily peak-load regulation with the same valley-load flow but of different "flow difference" (peak-load flow) (Figure 7). S4 and S6 to S9 are operation solutions of the same daily average discharge flow but different combinations of the valley-load flow and the flow difference (Figure 7). S10 and S11 are operation solutions without daily peak-load regulation in which a rise or a fall in water level lasts for 2 weeks (Figure 8). These two scenarios can be used to show the influence of water level variation on algal blooms when compared with S1. 
Table 4. Comparisons of Chla concentration and algal bloom levels of the outbreak reach.

\begin{tabular}{|c|c|c|c|c|c|c|c|c|c|c|c|c|}
\hline \multirow{2}{*}{$\begin{array}{c}\text { Operation } \\
\text { Type }\end{array}$} & \multirow[t]{2}{*}{ Scenario } & \multirow{2}{*}{$\begin{array}{l}\text { Operation } \\
\text { Factor }\end{array}$} & \multirow{2}{*}{$\begin{array}{c}\text { Peak } \\
\text { Moment } \\
\text { (Julian Day) }\end{array}$} & \multirow{2}{*}{$\begin{array}{c}\text { Maximum } \\
\text { Chla }(\mu \mathrm{g} / \mathrm{L})\end{array}$} & \multirow{2}{*}{$\begin{array}{c}\text { Reduced Rate } \\
\text { of Maximum } \\
\text { Chla (\%) } \\
\end{array}$} & \multicolumn{2}{|c|}{$\begin{array}{c}\text { Coverage Length } \\
\text { at the Peak Moment }\end{array}$} & \multirow{2}{*}{$\begin{array}{c}\text { Average } \\
\text { Chla } \\
(\mu \mathrm{g} / \mathrm{L})\end{array}$} & \multirow{2}{*}{$\begin{array}{c}\text { Reduced Rate } \\
\text { of Average } \\
\text { Chla (\%) } \\
\end{array}$} & \multicolumn{3}{|c|}{$\begin{array}{c}\text { Outbreak Duration } \\
\text { (day) }\end{array}$} \\
\hline & & & & & & Boundary ${ }^{\text {a }}(\mathbf{k m})$ & Length (km) & & & (1) & $(2)$ & (1)-(2) \\
\hline \multirow{9}{*}{$\begin{array}{l}\text { Short-term } \\
\text { operation }\end{array}$} & S1 & $\mathbf{0}$ & 25.75 & 117.76 & 0.00 & $28.5-17.5$ & 11.0 & 93.71 & 0.00 & 15 & 35 & 20 \\
\hline & S2 & $4000+6000$ & 26.75 & 115.51 & 1.91 & $28.5-18.5$ & 10.0 & 93.59 & 0.13 & 15 & 33 & 18 \\
\hline & S3 & $4000+8000$ & 25.75 & 108.31 & 8.02 & $28.5-19$ & 9.5 & 90.17 & 3.78 & 15 & 33 & 18 \\
\hline & S4 & $4000+10000$ & 24.75 & 103.10 & 12.45 & $28.5-19$ & 9.5 & 85.16 & 9.13 & 15 & 33 & 18 \\
\hline & S5 & $4000+12000$ & 23.75 & 94.31 & 19.92 & $28.5-19.5$ & 9.0 & 80.90 & 13.67 & 15 & 31 & 16 \\
\hline & S6 & $2000+13967$ & 23.75 & 92.47 & 21.48 & $28.5-20.0$ & 8.5 & 79.76 & 14.89 & 15 & 29 & 14 \\
\hline & S7 & $3000+11983$ & 23.75 & 97.68 & 17.05 & $28.5-19.0$ & 9.5 & 81.74 & 12.78 & 15 & 30 & 15 \\
\hline & S8 & $5000+8017$ & 24.75 & 105.40 & 10.49 & $28.5-18.5$ & 10.0 & 87.67 & 6.45 & 15 & 33 & 18 \\
\hline & S9 & $6000+6033$ & 24.75 & 107.89 & 8.38 & $28.5-18.0$ & 10.5 & 88.53 & 5.53 & 15 & 34 & 19 \\
\hline \multirow{2}{*}{$\begin{array}{l}\text { Medium-term } \\
\text { operation }\end{array}$} & S10 & $\begin{array}{c}160-167 \mathrm{~m} \\
(0.5 \mathrm{~m} / \mathrm{d})\end{array}$ & 22.75 & 80.14 & 31.95 & $30.5-21.0$ & 9.5 & 72.74 & 22.38 & 15 & 26 & 11 \\
\hline & S11 & $\begin{array}{c}160-153 \mathrm{~m} \\
(0.5 \mathrm{~m} / \mathrm{d})\end{array}$ & 32.75 & 156.91 & -33.24 & $26.5-14.0$ & 12.5 & 111.52 & -19.00 & 16 & 40 & $24+{ }^{b}$ \\
\hline
\end{tabular}

Notes: a Distances from the confluence of the two boundaries where the algal blooms occurred; ${ }^{\mathrm{b}}$ The algal bloom in the scenario of water level fall is still in the occurrence at the end of the simulation, thus the duration is more than 24 days. 


\subsection{Results and Analysis}

Because the 11 scenarios have the same nutrient, illumination and meteorology conditions, the differences of simulation results on algal blooms are mainly caused by different hydrodynamic conditions due to the change in reservoir operation. The simulated basic flow field of XXR indicates that water from the mainstream plunges from the upper layers into XXR and outflow of XXR discharges from the lower layers stably as a result of the water temperature difference between the two river branches. The water flowing from the upstream towards the downstream is defined as positive flow and water in the opposite direction is defined as negative flow. The negative flow can only reach the distance of $29 \mathrm{~km}$ from the confluence approximately within the backwater zone, because the reach of further upstream represents the river-type characteristic and the positive velocity is rather large that plunging flow cannot go forward any more.

The baseline conditions: Take S1 as an example to describe a simulated algal bloom process for this study as it does not have any intervening reservoir operation. The contour plots of Chla concentration on four different Julian days, from the beginning to the end day of the 40-day simulation period, are shown in Figure 9. The vertical distribution of velocity vectors at various locations along the longitudinal direction are also shown in the figure, which reflect the above-described flow field and also indicate the transport process of algae. (Note the distance shown on the horizontal axis is from upstream to downstream ends.) Algae primarily grow in the upper layers and emerge in the water surface which is influenced mainly by the negative flow. The negative flow pushes the algae towards the upstream of XXR, and the concentration of algae at the confluence is diluted at first since Chla concentration of the mainstream of TGR is always lower than that in XXR [2]. When the algae reaches the upper boundary of the backwater zone, the combined effects of continuous pushing of negative flow and large flow of river-type reach at the farthest upstream force the algae move downwards into the deep water where they die gradually without light penetrating into. Thus, the whole transport process of algae is an anticlockwise motion.

The temporal variations of Chla concentration on the water surface at typical stations under S1 are shown in Figure 10. The longitudinal distributions of Chla on the water surface at different times during the simulation period are shown in Figure 11. Chla at confluence is diluted from the beginning, but Chla in the downstream, midstream, and upstream all go through the increase and decrease phases. At the upper reach, the increase time is longer and the peak value is larger. From the longitudinal distribution, Chla in the downstream decreases throughout the simulation but increases in the upper stream with a coverage length of high concentration shrinking before it reaches the peak value. The peak value of Chla $117.76 \mu \mathrm{g} / \mathrm{L}$ occurs at Julian Day 25.75 around the reach $26 \mathrm{~km}$ from the confluence. Then, the reach of $17.5-28.5 \mathrm{~km}$ from the confluence is entirely covered by the algal bloom. The algal bloom in S1 lasts for 20 days all together. So, the Chla concentration along the upstream reach reflects the highest level of algal bloom in XXR, where it occurs more easily, is more severe and lasts longer. 
Figure 9. Transport process for algae in XXR under the baseline condition S1.
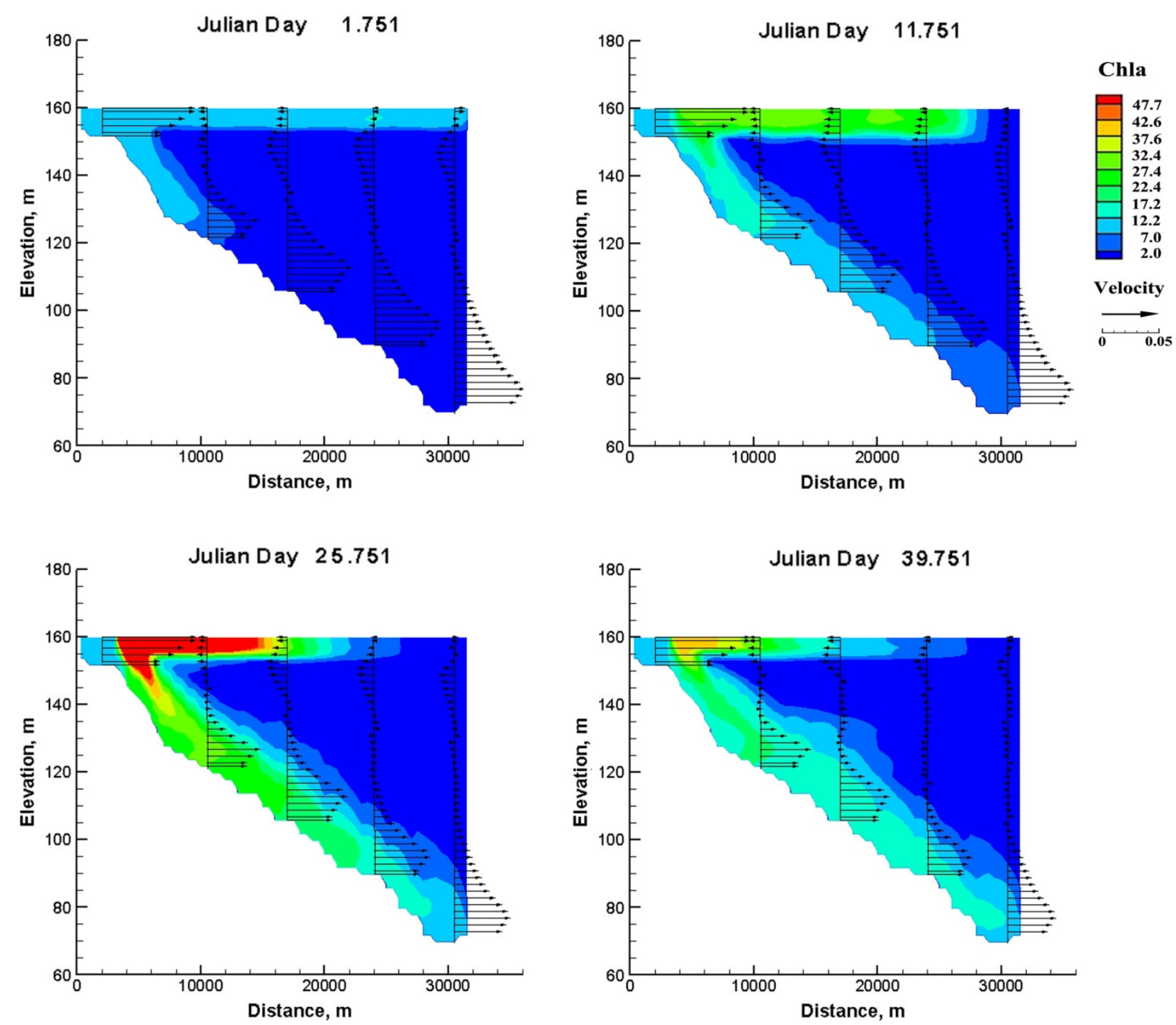

Figure 10. Temporal variation of Chla concentration in water surface of XXR at typical stations on $\mathrm{S} 1$.

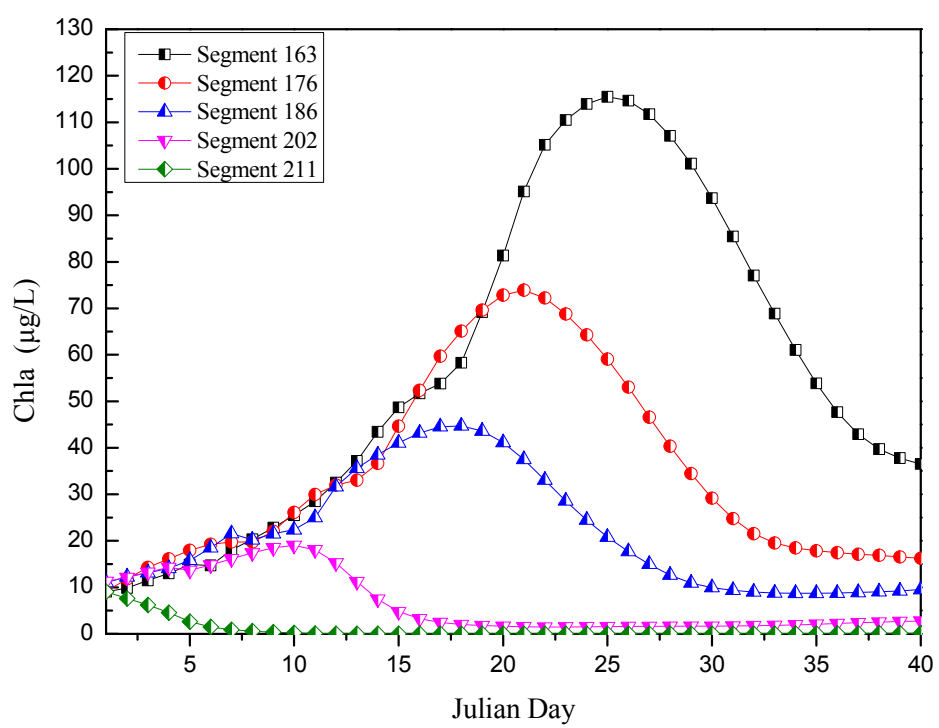


Figure 11. Longitudinal distribution of Chla concentration in water surface of XXR on S1.

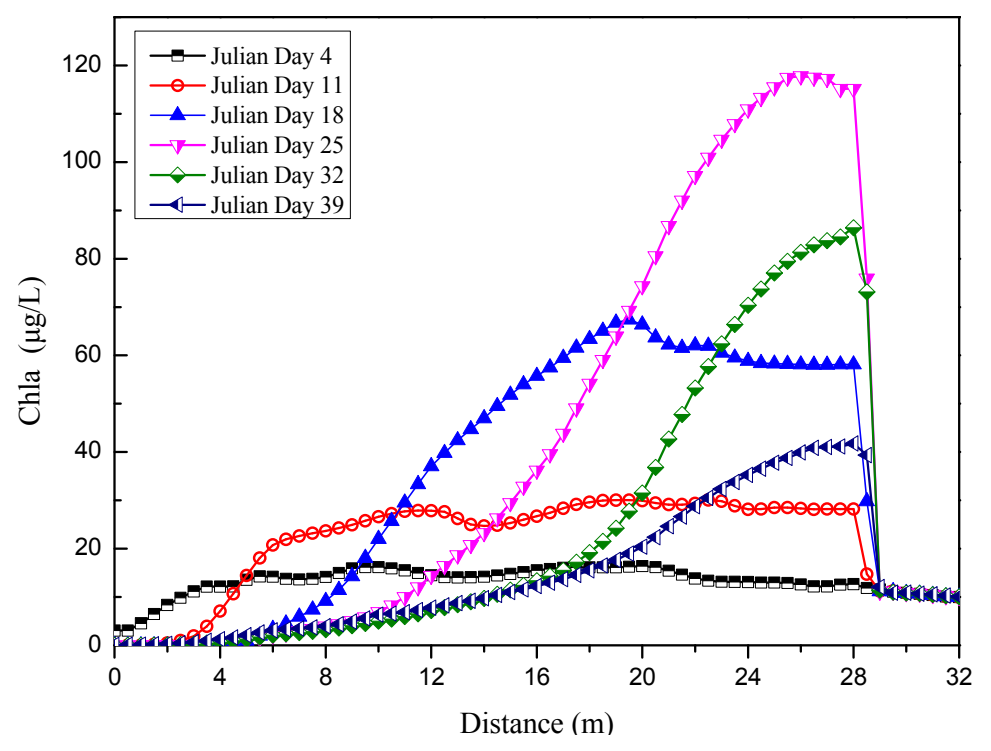

The reservoir operation: Based on the flow field and algal bloom process in S1, reservoir operation is used to accelerate the transport process of algae by enhancing the water exchange between the two river branches, in order to reduce the algal bloom level. As described above, the strength of flow field in S1, S10 and S11 is constant but fluctuates in S4 with peak-load regulation throughout a day. The contour plots of Chla concentration on Julian Day 14 (considered as the end day of operation under the scenarios of water level variation) under the four primary scenarios S1, S4, S10 and S11 are shown in Figure 12. The vertical distribution of velocity vectors at various locations along the longitudinal direction are also shown in Figure 12. These plots reflect the same flow field and algae transport process of algae, but at different magnitudes to be specifically described below.

Specific and quantitative effects of the short-term peak-load regulation: The plunging flow and discharge flow, defined as the flow rate through the segment of XXR confluence (Segment 211) can be calculated by the negative and positive velocity multiplied by river section area, which are obvious indicators of water exchange between the two river branches. Figure 13 shows the flow value of each hour during a day in S4 respectively in comparison to S1. The plunging flow and discharge flow in S1 (the baseline condition) are constant and their difference is also a constant that is equal to the XXR inflow $\left(65.5 \mathrm{~m}^{3} / \mathrm{s}\right)$, but they fluctuate strongly in $\mathrm{S} 4$ with the reservoir's daily peak-load (flow) regulation. For the most time, the plunging flow in S4 is much larger and the discharging flow is at the same time much smaller than S1. For the entire day, water from the mainstream plunges into XXR and discharges out of XXR in S4 are both much larger than S1. Thus, flow fluctuation through the peak-load regulation is an effective way of strengthening the water exchange between the two branches (between the mainstream and the tributary). The velocity vectors shown in Figure 12 are at the moment (at 0 o'clock) when the plunging flow is the largest during the day. It can be obviously seen that all the velocities of negative (plunging) flow in S4 are larger than S1. Then, the more intensive plunging flow will push the algae towards the upstream and moved into deep water faster. Just as the contour plot shows, the coverage area of algae in S4 is smaller than S1 and the Chla concentration is also lower than $\mathrm{S} 1$. Therefore, the daily peak-load regulation is an effective way of reducing the level of algal bloom. 
Figure 12. Contour plot of Chla concentration and vector plot of longitudinal velocity at Julian Day 14.00.
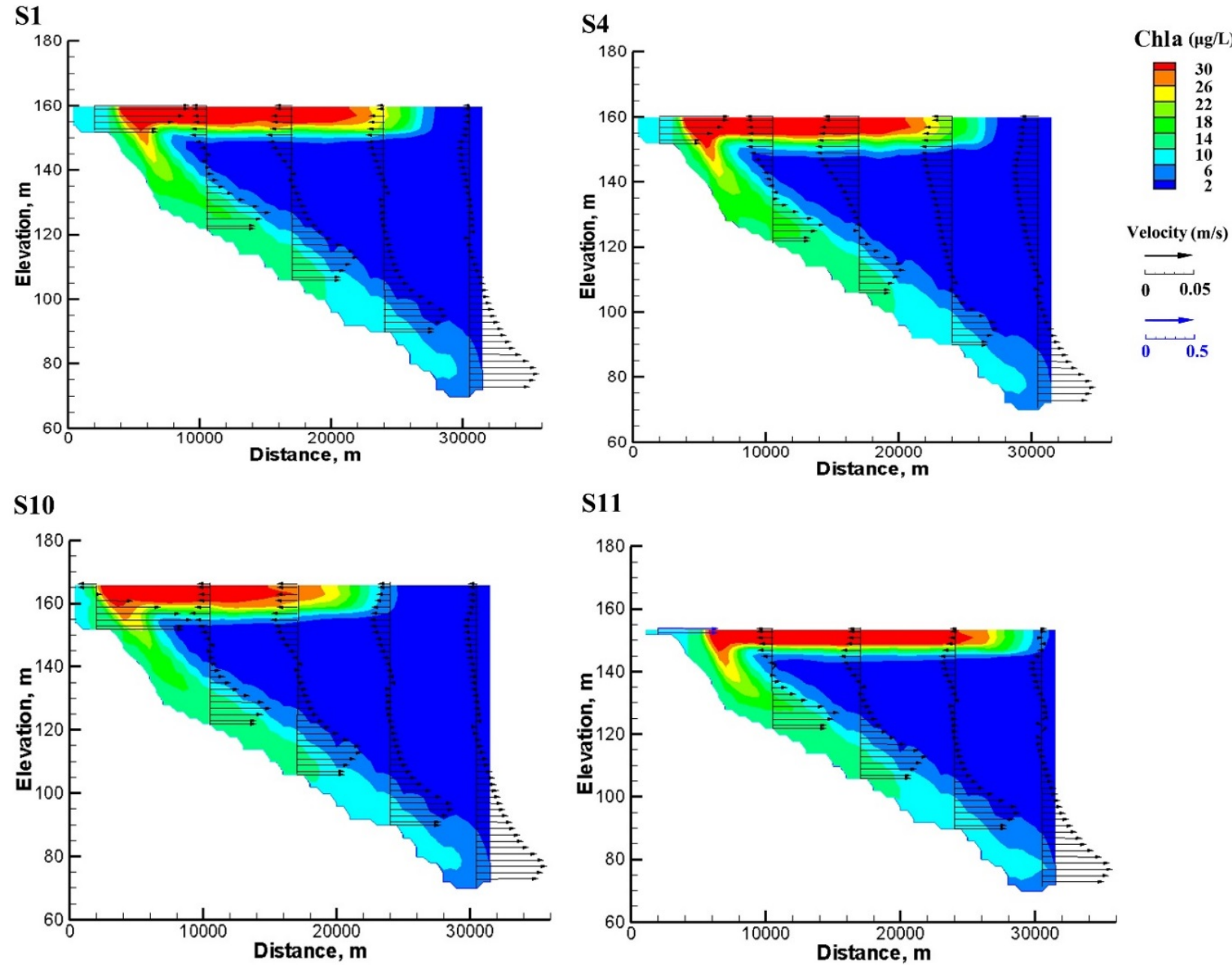

Figure 13. Daily plunging flow and discharge flow at XXR confluence.

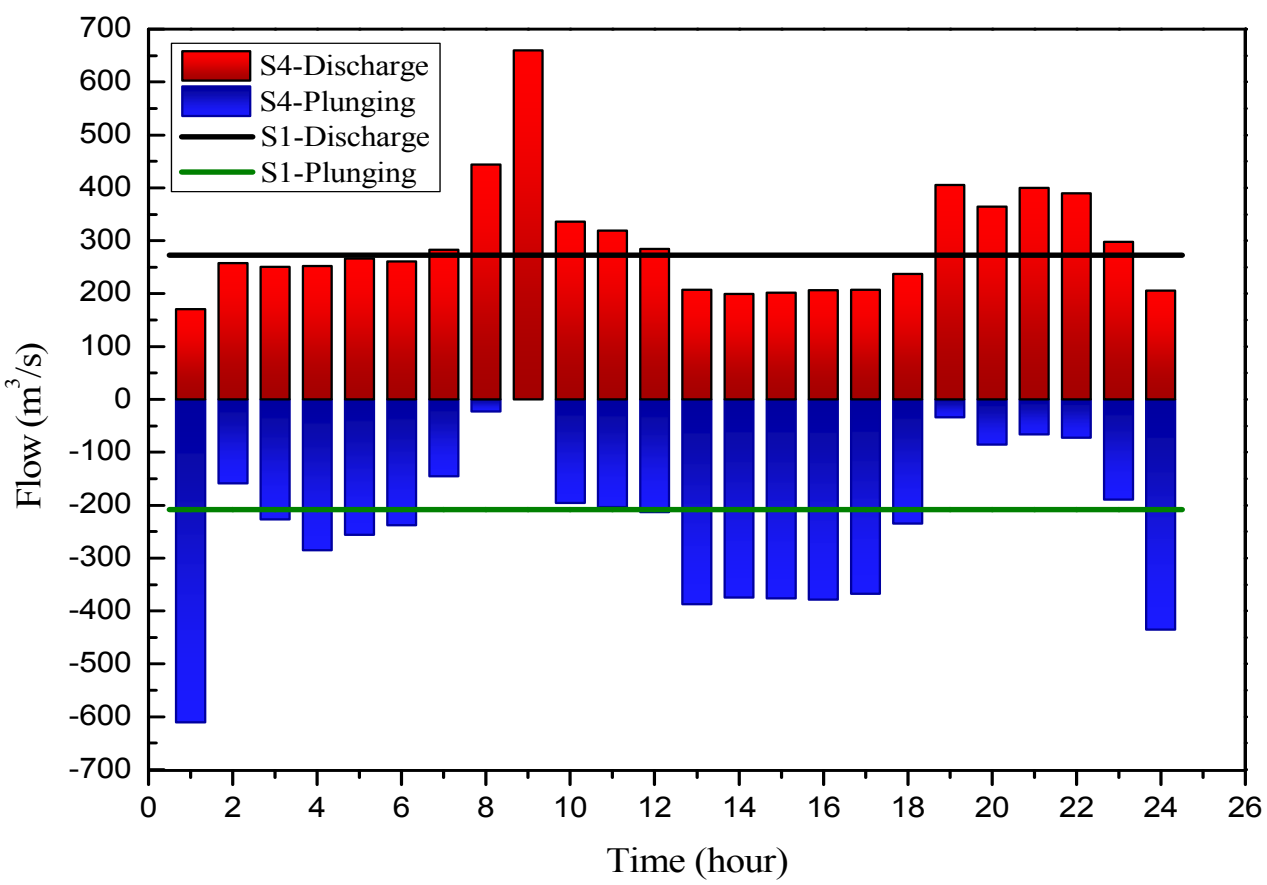


Specific and quantitative effects of the medium-term water level variation: Compared with S1, water level variations in S10 and S11 primarily change the vertical velocity distribution of XXR in the upper layers, as shown in Figure 12. The thickness of plunging flow layer is much larger with larger velocity in S10 than S1, but the thickness is much smaller in S11 with lower velocity than S1. The discharge flows under all the three scenarios (S1, S10 and S11) have minor differences, however, a much larger amount of water from the mainstream plunges into XXR in S10 resulting in a stronger dilution effect as well as faster upstream transport of algae and leading to lower Chla concentration. On the contrary, a much smaller amount of water from the mainstream plunges into XXR in S11, resulting in the slower transport process, decreased water volume and weaker dilution effect, higher Chla concentration and larger coverage area of algae. At the same time, as indicated before, the velocity of the river-type reach is rather high that algae cannot be transported all the way upstream. In conclusion, the water level rise, similar to the peak-load regulation demonstrated above, is also effective for reducing the algal bloom level by strengthening the flow plunging into XXR to accelerate the upstream transport process of algae.

Different levels of the effects resulted from various values of reservoir operation factors: Different values of operation factors have different levels of effect on the reduction of algal blooms. The temporal variations of Chla concentration at Segment 163 of various operational scenarios are compared in Figure 14. The major indicators of algal bloom levels are listed in Table 4, and all the Chla concentrations refer to that on the water surface. The time when the algal bloom reaches the highest level is listed in the fourth column. The maximum Chla concentration and the average Chla concentration along the outbreak reach at this time are shown in Figure 15 with values listed in the fifth and ninth columns of the table. The respective reduced percentages of Chla concentration are calculated using Chla concentration of S1 as a benchmark and they are listed in the sixth and 10th columns. The coverage length and outbreak duration of algal blooms are also shown in Figure 16 with their values listed in the table.

From the whole growth process of algae shown in Figure 14, it can be observed that differences in Chla concentration under different operation scenarios reveal themselves mostly from the time when the algal bloom begins to occur. The Chla concentration decreases with the larger flow difference under the same valley-load flow, with the lower valley-load flow plus the larger flow difference under the same daily average discharge flow, and as the water level rises. The four quantitative indicators of the algal bloom level are shown in Figure 15 and Figure 16 for various operation scenarios. They demonstrate the rather similar impacts. Combined with the understanding of the hydrodynamic process with the specific values of indicators in the table, it can be observed that the scenario with a larger flow difference under the same valley-load flow has a larger plunging flow, higher velocities and a shorter transport process. Thus, the algal bloom reaches the peak value earlier but the values are lower, and the algal bloom level is also lower with a shorter coverage length and shorter outbreak duration. Owing to the same reason, the scenario with a lower valley-load flow and larger flow difference under the same daily discharge flow works better on the reduction of algae concentration.

Among all the operation factors, the effect of water level rise is the most significant. Compared with the scenario without any regulation (S1), the coverage length is shrunk by $1.5 \mathrm{~km}$, the outbreak duration is shortened by 9 days (an almost one half reduction, reduced from 20 to 11 days), and the average and maximum Chla concentrations are reduced by $22.38 \%$ and $31.95 \%$ (almost one third 
reduction), respectively. However, the water level fall makes the algal bloom problem worse as the maximum Chla concentration on the contrary increases by $33.24 \%$ (about one third increase) and the algal bloom lasts beyond the end of the simulation (with the algal bloom duration longer than 24 days).

Figure 14. Temporal variations of Chla concentrations of upstream of XXR (Segment 163) under different operation factors. (a) the same valley-load flow but different flow differences; (b) the same daily water discharge but different combinations of valley-load flows and peak-load flows; (c) different water level variations.

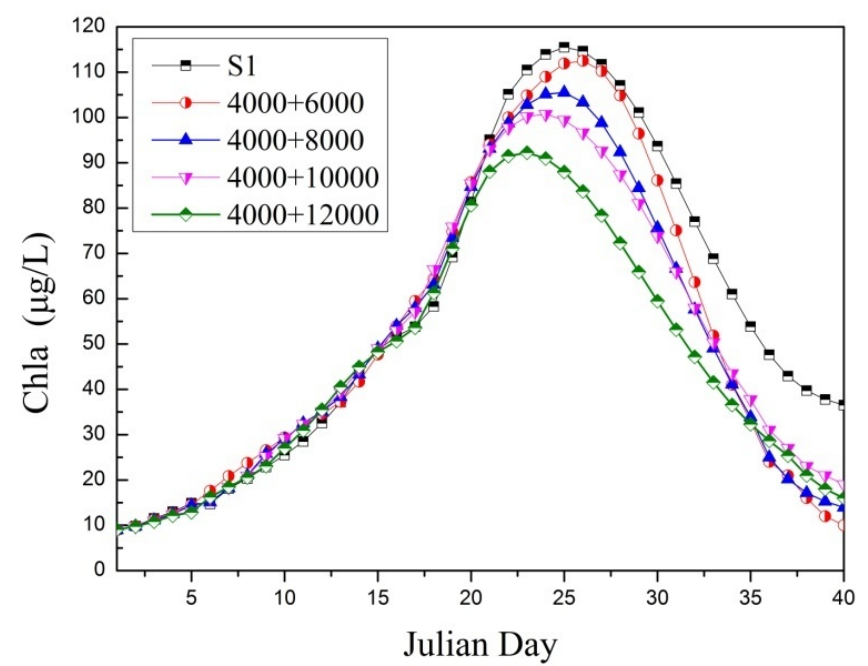

(a)

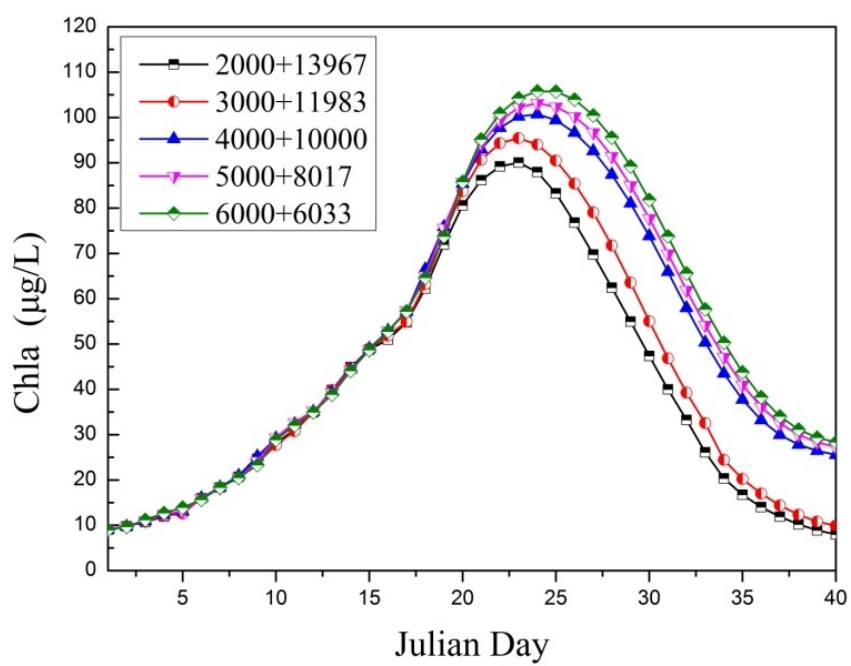

(b)

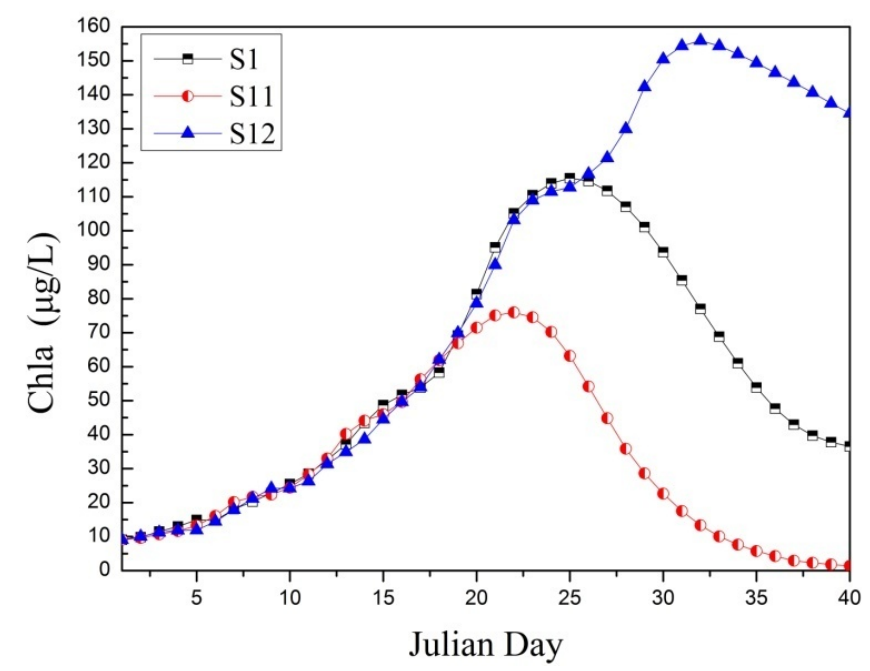

(c)

Reservoir operation rules for reducing algal bloom level: As demonstrated through the hydrodynamic and water quality modeling analysis in this study, the daily peak-load regulation will help to reduce the level of algal bloom. It should be conducted for short-term operation with a larger flow difference under the same valley-load flow or a combination of the lower valley-load flow and the higher flow difference under the same daily average discharge flow. Also, the water level rise can be conducted for the medium-term operation (e.g., over two weeks). With both of these types of reservoir operation being favorable to the algal bloom level reduction, they can be combined together periodically as a long-term operation (e.g., monthly) in the non-flood season for TGR. 
Figure 15. Maximum and average Chla concentration of algal blooms.

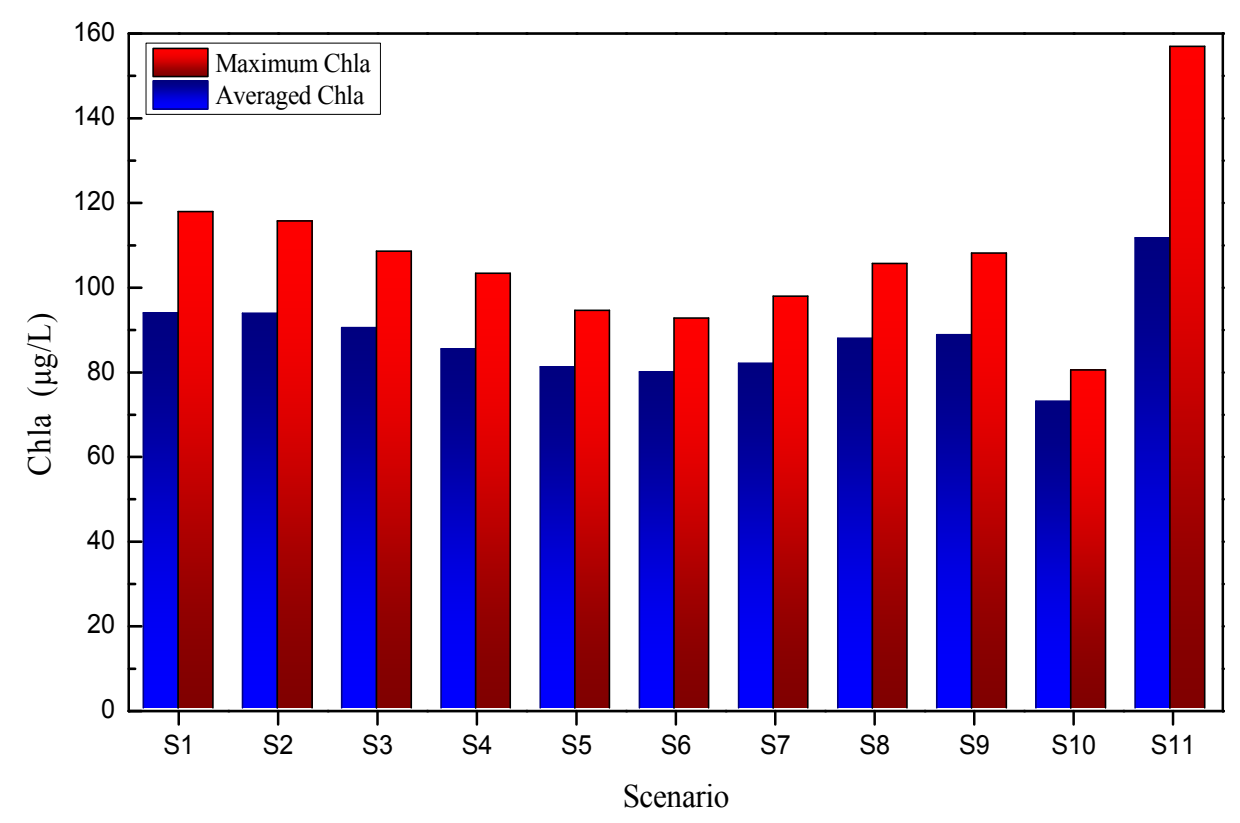

Figure 16. Coverage length and outbreak duration of algal blooms.

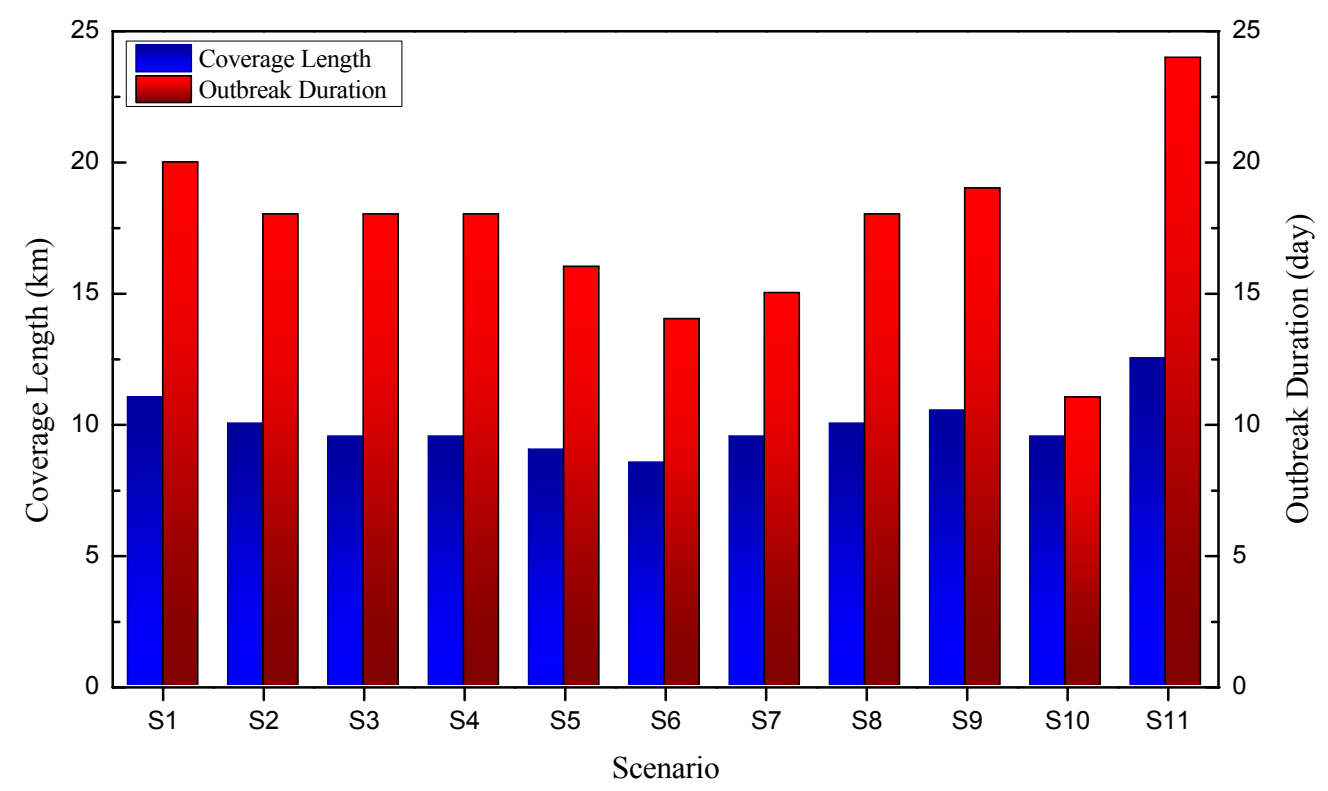

Multi-objective reservoir operation: It has been demonstrated that the peak-load regulation can improve the utilization efficiency of electricity generated and the raising reservoir level is beneficial for energy storage and hydropower generation [40]. Therefore, an integration of the daily operation and medium-term operation is not only a feasible way for improving the hydrodynamic conditions and water quality, but also a probable way to achieve multi-objective regulation for both hydropower generation and water environment improvement.

For the future work, with the runoff, electricity generation demand and the regulations of cascade reservoirs considered, influence of multi-time scale operation on the eutrophication and algal blooms in the tributaries can be further investigated to propose more feasible operation rules. Then, an ecology-friendly, multi-objective, and multi-scale optimal operation for TGR can be achieved. 


\section{Conclusions}

The occurrence of algal blooms in near-dam tributaries of TGR in the studied non-flood season is caused by the slow water motion that provides suitable environment for algae growth, together with the unfavorable meteorological conditions (e.g., warm air, low wind) and the high nutrient load. To regulate the hydrodynamic conditions to reduce algal blooms, a two-dimensional, laterally averaged hydrodynamic and water quality model based on the CE-QUAL-W2 model for TGR and XXR is developed and applied to study the influences of reservoir operations on the algal blooms.

The formulation of reservoir operation rules is based on the current scheduling rules of TGHS as well as the scenario simulations. The reservoir operation will be helpful for water quality improvement as it will enhance water exchange between the mainstream of TGR and the XXR tributary resulting in more water from the mainstream plunging into XXR leading to the higher dilution as well as the acceleration of the upstream transport process of algae. Through the comparisons of algal bloom levels under different values of operation factors, the operation rules oriented to water environment improvement are formulated. For the short-term operation, daily peak-load regulation should be conducted with a larger flow difference under the same valley-load flow, or a combination of the lower valley-load flow and a higher flow difference under the same daily average discharge flow. For the medium-term operation (e.g., over two weeks), water level rise can be conducted. For the long-term operation (e.g., over months), the short-term flow regulation and medium-term water level rise can be combined periodically in the non-flood season for TGR.

\section{Acknowledgments}

The research was supported by the Science Fund for Creative Research Groups of the National Natural Science Foundation of China (51321065), National Natural Science Foundation of China (51109156), Major National Science and Technology Project (2012ZX07205005), Specialized Research Fund for the Doctoral Program of Higher Education (20100032120048), the Programme of Introducing Talents of Discipline to Universities (B14012), and the key project of National Natural Science Fund of Tianjin (13JCZDJC36200). The writers acknowledge engineers in China Three Gorges Corporation and colleagues in the group of Defu Liu in China Three Gorges University for their help on data collection. And the writers also acknowledge the assistance of anonymous reviewers.

\section{Author Contributions}

The idea and approach for the study was confirmed by Chao Ma and Jijian Lian. The majority of the numerical modeling and analysis work was conducted by Ye Yao and Chao Ma with the assistance of Qizhong Guo who also gave important advices on writing. All the authors were involved in preparation of the manuscript.

\section{Conflicts of Interest}

The authors declare no conflict of interest. 


\section{References}

1. Dai, H.C.; Mao, J.Q.; Jiang, D.G.; Wang, L.L. Longitudinal hydrodynamic characteristics in reservoir tributary embayments and effects on algal blooms. PLoS One 2013, 8, 1-14.

2. Yang, Z.J.; Liu, D.F.; Ji, D.B.; Xiao, S.B. Influence of the impounding process of the Three Gorges Reservoir up to water level $172.5 \mathrm{~m}$ on water eutrophication in the Xiangxi Bay. Sci. China Technol. Sci. 2010, 53, 358-369.

3. Executive Office of State Council TGP Construction Committee, Yangtze Water Resources Commission. Annual Report of Eco-environmental Monitoring of TGP Reservoir; Executive Office of State Council TGP Construction Committee, Yangtze Water Resources Commission: Wuhan, China, 2004-2013.

4. Wang, H.Y. Effects of the Three Gorges Reservoir on the water environment of the Xiangxi River with the proposal of countermeasures. Resour. Environ. Yangtze Basin 2005, 14, 233-237. (In Chinese)

5. Qiu, G.S.; Hu, S.; Ye, D.; Yu, A.L.; Zang, X.P. Investigation on the present situation of eutrophication and water bloom in the branches of Three Gorges Reservoir. Resour. Environ. Yangtze Basin 2011, 20, 311-316. (In Chinese)

6. Hans, W.P.; Rolland, S.F.; Pia, H.M.; Julianne, D. Harmful freshwater algal blooms, with an emphasis on cyanobacteria. ScientificWorld 2001, 1, 76-113.

7. Donald, M.A.; Patricia, M.G.; Joann, M.B. Harmful algal blooms and eutrophication: Nutrient sources, composition, and consequences. Estuaries 2002, 25, 704-726.

8. Kevin, G.S.; Gregory, J.D.; Gary, J.K. Harmful algal blooms: Causes, impacts and detection. J. Ind. Microbiol. Biotechnol. 2003, 30, 384-406.

9. Li, J.X.; Yu, X.Z.; Xing, Z.G. Eutrophication model for the branch of Three Gorges Reservoir. Adv. Water Sci. 2005, 16, 777-783. (In Chinese)

10. Huang, C.; Zhong, C.H.; Deng, C.G.; Xing, Z.G.; Li, Y.J.; Wang, D.R.; Meng, W.L. Preliminary study on correlation between flow velocity and algae along Daning River's backwater region at sluice initial stages in the Three Gorges Reservoir. J. Agro Environ. Sci. 2006, 25, 453-457.

11. Huang, Y.L. Study on the Formation and Disappearance Mechanism of Algal Bloom in the Xiangxi River Bay at Three Gorges Reservoir. Ph.D. Thesis, College of Water Resources and Architectural Engineering, Northwest Agriculture \& Forestry University, Xianyang, China, September 2007. (In Chinese)

12. Yang, Z.J.; Xu, Y.Y.; Ji, D.B.; Liu, D.F. On correlative factors influencing chlorophyll a in reservoir bay of Xiangxi river in spring. Yangtze River 2008, 39, 33-35. (In Chinese)

13. Yi, Z.Q.; Liu, D.F.; Yang, Z.J.; Ma, J.; Ji, D.B. Water temperature structure and impact of which on the bloom in spring in Xiangxi Bay at Three Gorges Reservoir. J. Hydroecol. 2009, 2, 6-10.

14. Wang, L.L.; Dai, H.C.; Cai, Q.H. Numerical predicting of velocity and Chla in Xiangxi River and correlativity research. J. Basic Sci. Eng. 2009, 17, 652-658.

15. Zeng, H.; Song, L.R.; Yu, Z.G. Preliminary study on algal blooms within the Three Gorges Reservoir. Resour. Environ. Yangtze Basin 2007, 16, 336-339. (In Chinese) 
16. Holbach, A.; Wang, L.J.; Chen, H.; Hu, W.; Schleicher, N.; Zheng, B.H.; Norra, S. Water mass interaction in the confluence zone of the Daning River and the Yangtze River-a driving force for algal growth in the Three Gorges Reservoir. Environ. Sci. Pollut. Res. 2013, 20, 7027-7037.

17. Wu, T.F.; Qin, B.Q.; Zhu, G.W.; Luo, L.C.; Ding, Y.Q.; Bian, G.Y. Dynamics of cyanobacterial bloom formation during short-term hydrodynamic fluctuation in a large shallow, eutrophic, and wind-exposed Lake Taihu, China. Environ. Sci. Pollut. Res. 2013, 20, 8546-8556.

18. Ji, D.B.; Liu, D.F.; Yang, Z.J. Hydrodynamic characteristics of Xiangxi Bay in Three Gorges Reservoir. Sci. China 2010, 40, 101-112.

19. Jiang, D.G.; Dai, H.C.; Liu, W. Influence of thermal density flow on hydrodynamics of Xiangxi Bay in Three Georges Reservoir, China. Procedia Environ. Sci. 2011, 10, 1637-1645.

20. Zheng, T.G.; Mao, J.Q.; Dai, H.C.; Liu, D.F. Impacts of water release operations on algal blooms in a tributary bay of Three Gorges Reservoir. Sci. China Technol. Sci. 2011, 54, 1588-1598.

21. Liu, L.; Liu, D.F.; Johnson, D.M.; Yi, Z.Q.; Huang, Y.L. Effects of vertical mixing on phytoplankton blooms in Xiangxi Bay of Three Gorges Reservoir: Implications for management. Water Res. 2012, 46, 2121-2130.

22. Cao, C.J.; Zheng, B.H.; Chen, Z.L.; Huang, M.S.; Zhang, J.L. Eutrophication and algal blooms in channel type reservoirs: A novel enclosure experiment by changing light intensity. J. Environ. Sci. China 2011, 23, 1660-1670.

23. Li, J.; Li, D.X.; Wang, X.K. Three-dimensional unstructured-mesh eutrophication model and its application to the Xiangxi River, China. J. Environ. Sci. China 2012, 24, 1569-1578.

24. Wang, L.P.; Zheng, B.H. Prediction of chlorophyll-a in the Daning River of Three Gorges Reservoir by principal component scores in multiple linear regression models. Water Sci. Technol. 2013, 67, 1150-1158.

25. Zhou, J.J. Discussion on Three Gorges Powerplant to modulate more net-peaks to improve water quality of tributaries of reservoir. Sci. Technol. Rev. 2005, 23, 8-11. (In Chinese)

26. Zhou, J.J. Improvement of eco-environmental conditions of Three Gorges Reservoir by optimal operations. Perspective 2008, 26, 64-71. (In Chinese)

27. Ma, C. Research on Multi-Scale and Multi-Objective Combined Optimal Dispatching of Cascaded Hydropower Junctions. Ph.D. Thesis, School of Civil Engineering, Tianjin University, Tianjin, China, June 2008. (In Chinese)

28. Ma, C.; Lian, J.J. Preliminary research on influence mechanism of human controlled dispatching solutions to hydrodynamics and water quality of tributaries of reservoir. J. Tianjin Univ. 2011, 44, 202-209. (In Chinese)

29. Rajendra, G.K.; David, P.H.; Robert, L.P. Comparison of two 2-dimensional, laterally averaged hydrodynamic model applications to the Swan River Estuary. Math. Comput. Simul. 2000, 51, 627-638.

30. Bartholow, J.; Hanna, R.B.; Saito, L.; Lieberman, D.; Horn, M. Simulated limnological effects of the Shasta Lake temperature control device. Environ. Manag. 2001, 27, 609-626.

31. Sullivan, A.B.; Jager, H.I.; Myers, R. Modeling white sturgeon movement in a reservoir: The effect of water quality and sturgeon density. Ecol. Model. 2003, 167, 97-114. 
32. Tim, K.; Robert, L.A.; Chris, B.; Scott, A.W. Green River CE-QUAL-W2 Project: A Hydrodynamic and Water Quality Study of the Green River King County, Washington; Technology Report; Portland State University: Portland, OR, USA, 2004.

33. Gregory, E.N.; Andrea, B. Comparison of two stream temperature models and evaluation of potential management alternatives for the Speed River, Southern Ontario. J. Environ. Manag. 2009, 90, 866-878.

34. Afshar, A.; Kazemi, H.; Saadatpour, M. Particle swarm optimization for automatic calibration of large scale water quality model (CE-QUAL-W2): Application to Karkheh Reservoir, Iran. Water Resour. Manag. 2010, 25, 2613-2632.

35. Cole, T.M.; Wells, S.A. CE-QUAL-W2: A Two-Dimensional, Laterally Averaged, Hydrodynamic and Water Quality Model, Version 3.6; User Manual; Instruction Report EL-08-1; U.S. Army Corps of Engineers Waterways Experiment Station: Vicksburg, MS, Washington, DC, USA, 2008.

36. Lian, J.J.; Yao, Y.; Ma, C. Emergency regulation strategy for sudden algal bloom accidents of Xiangxi River in Spring. J. Tianjin Univ. Sci. Technol. 2013, 4, 291-297. (In Chinese)

37. Wang, L.L.; Dai, H.C.; Cai, Q.H. Simulation of eutrophication in branch of channel-type reservoirs. J. Sichuan Univ. 2009, 41, 18-23.

38. Okubo, A. Oceanic diffusion diagrams. Deep Sea Res. 1971, 18, 789.

39. Moriasi, D.N.; Arnold, J.G.; van Liew, M.W.; Bingner, R.L.; Harmel, R.D.; Veith, T.L. Model evaluation guidelines for systematic quantification of accuracy in watershed simulations. Am. Soc. Agric. Biol. Eng. 2007, 50, 885-900.

40. Ma, C.; Lian, J.J.; Wang, J.N. Short-term optimal operation of Three Gorges and Gezhouba cascade hydropower stations in non-flood season with operation rules from data mining. Energy Convers. Manag. 2013, 65, 616-627.

41. Labaugh, J.W. Relation of algal biovolume to chl a in selected lakes and wetlands in north-central United States. Can. J. Fishe. Aquat. Sci. 1995, 52, 41-424.

42. Cao, Q.L. Study on the Motion Characteristics of Reverse Density Currents in Xiangxi Bay of the Three-Gorge Reservoir. Master's Thesis, College of Civil and Hydroelectric Engineering, China Three Gorges University, Yichang, China, May 2010. (In Chinese)

43. Zhang, Y.; Liu, D.F.; Ji, D.B.; Yang, Z.J.; Yang, Z.J. Effects of intrusions from Three Gorges Reservoir on nutrient supply to Xiangxi Bay. Environ. Sci. 2012, 33, 2621-2627. (In Chinese)

44. Xu, Y.Y.; Cai, Q.H.; Han, X.Q.; Shao, M.L.; Liu, R.Q. Factors regulating trophic status in a large subtropical reservoir, China. Environ. Monit. Assess. 2010, 169, 237-248.

45. Zheng, B.H.; Zhang, Y.; Fu, G.; Liu, H.L. On the assessment standards for nutrition status in the Three Gorge Reservoir. Acta Sci. Circumstantiae 2006, 26, 1022-1030. (In Chinese)

(C) 2014 by the authors; licensee MDPI, Basel, Switzerland. This article is an open access article distributed under the terms and conditions of the Creative Commons Attribution license (http://creativecommons.org/licenses/by/4.0/). 